\title{
Research Paper \\ The Relationship between Cognitive Bias, Anxiety Sensitivity and Maternal Beliefs and Anxiety in Children: The Mediating Role of Coping Strategies
}

Shirin Zeinali ${ }^{1}$, Hamid Poursharifi*2, Jalil Babapour ${ }^{3}$, Majid Mahmood Aliloo ${ }^{3}$, Zeynab Khanjani ${ }^{3}$

1. Assistant Professor, Department of Psychology, Faculty of Literature and Humanities, Urmia University, Iran

2. Associate Professor, Department of Psychology, Faculty of Psychology, University of Social Welfare and Rehabilitation Sciences, Tehran, Iran

3. Professor, Department of Psychology, Faculty of Educational Sciences and Psychology, University of Tabriz, Iran

Citation: Zeinali S, Poursharifi H, Babapour J, Mahmood Aliloo M, Khanjani Z. The relationship between cognitive bias, anxiety sensitivity and maternal beliefs and anxiety in children: the mediating role of coping strategies. Quarterly Journal of Child Mental Health. 2020; 7(3): 5366.

http://dx.doi.org/10.52547/jcmh.7.3.6

\section{A R T I C L E I N F O}

\section{Keywords:}

Anxiety sensitivity, cognitive bias, maternal beliefs about anxiety, coping strategies, anxiety

Received: 31 May 2020 Accepted: 6 Sep 2020 Available: 7 Dec 2020

\section{A B S T R A C T}

Background and Purpose: Anxiety is a common disorder in children which may be influenced by several interpersonal and intrapersonal factors. Based on the studies done, it seems that the components of thought, feeling and behavior of parents and children influence the anxiety in children. This study aimed to investigate the relationship between cognitive bias, anxiety sensitivity and maternal beliefs and anxiety in children through the mediating role of coping strategies in children.

Methods: This research was a descriptive-correlational research. The study population consisted of all the students of grade 5 and 6 (i.e. 11-12 years old) studying at the non-governmental schools of District 3 in Tabriz city in the academic year of 2015-2016. Among which, a sample of 279 students (150 girls and 129 boys) together with their mothers were selected by cluster sampling. Anxiety Sensitivity Index (Tsao et al., 2006), Cognitive Error Questionnaire (Covin et al., 2011), Coping Strategies Questionnaire (Hernandez, 2008), Anxiety Questionnaire (March et al., 2010) and Parental Beliefs about Anxiety Questionnaire (Chorpita, 2010) were used to gather the data. Correlation and path coefficient analysis were used to analyze the data.

Results: The results showed that anxiety sensitivity, maternal beliefs and coping strategies directly affect the anxiety in children. The result also indicated that anxiety sensitivity, cognitive bias and maternal beliefs had an indirect effect on the anxiety in children through the coping strategies $(\mathrm{p}=0.05)$.

Conclusion: Based on the results, it can be concluded that coping strategies play an important role in the relationship between anxiety sensitivity, cognitive bias, and maternal beliefs and anxiety in children. Therefore, cognitive training of mothers and children which improves the coping strategies in children can be very effective in reducing the anxiety in children.

\footnotetext{
* Corresponding author: Hamid Poursharifi, Associate Professor, Department of Psychology, Faculty of Psychology, University of Social Welfare and Rehabilitation Sciences, Tehran, Iran.

E-mail addresses: Poursharifih@gmail.com
} 


\title{
رابطه سو يرى شناختى، حساسيت اضطر ابى و باورهاى مادر با اضطراب كود ك: نقش واسطهاى راهبردهاى كنار آمدن
}

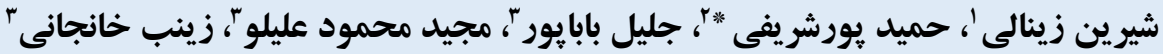

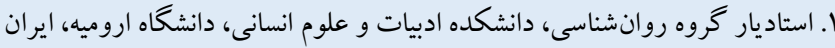

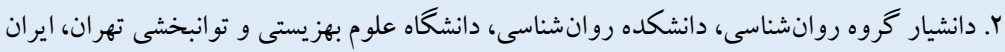

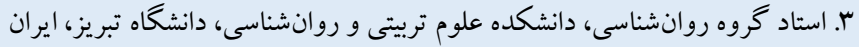

\begin{tabular}{|c|c|}
\hline جكيده & 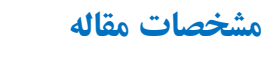 \\
\hline زمينه و هدف: اضطراب كود كان اختلالى شايع بوده و از عوامل متعدد درونفردى و بين فردى، تأثير مىيذيرد. بر اساس مطالعات انجام & 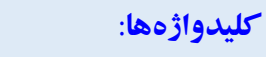 \\
\hline شده به نظر مىرسد مؤلفه هاى فكر، احساس، و رفتار والد و كود كى، تأثير متفاوتى بر اضطراب كود كان دارند. هدف از انجام اين اين يُووهش & حساسيت اضطرابى، \\
\hline تعيين رابطه سو گيرى شناختى، حساسيت اضطر ابى، و باورهاى مادر با اضطراب كو دكك با نقش واسطهاى راهبردهاى كنار آمدن كود كان بود. & 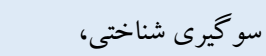 \\
\hline روش: روش اين يُزوهش، توصيفى از نوع همبستخى است. جامعه آمارى اين مطالعه شامل تمامى دانش آموزان بِيه ينجم و ششم مدارس & 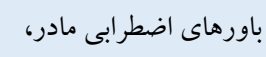 \\
\hline 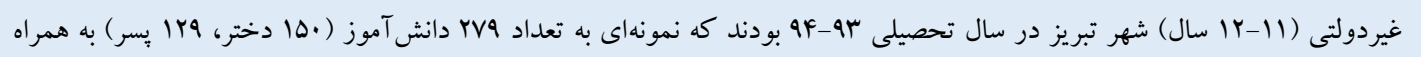 & راهبردهاى كنار آمدن، \\
\hline مادران آنها از مدارس ناحيه r آموزش و يرورش به روش نمونه گيرى خوشهاى انتخاب شدند. براى گردآورى دادهها از يرسشنامههاى & 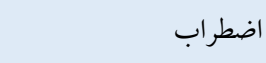 \\
\hline 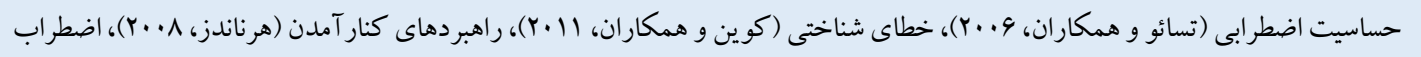 & \\
\hline \multicolumn{2}{|l|}{ 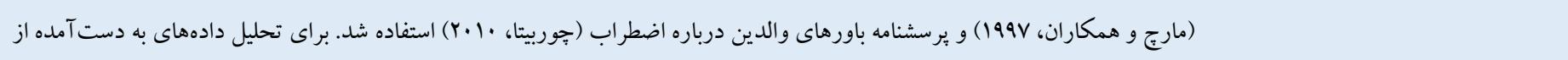 } \\
\hline روش همبستخى و تحليل مسير استفاده شد. & \\
\hline \multicolumn{2}{|l|}{ يافتها: نتايج نشان داد حساسيت اضطرابى، باورهاى مادر و راهبردهاى كنار آمدن، به صورت مستقيم بر اضطراب كودكان تأثير دارند. } \\
\hline \multirow{2}{*}{\multicolumn{2}{|c|}{ همجينين نتايج اين مطالعه حاكى از آن بود كه حساسيت اضطرابى، سو كيرى شناختى، و باورهاى مادر از طريق راهبردهاى كنار آمدن، بر }} \\
\hline & \\
\hline نتيجه كيرى: نتايج اين يزوهش نشان داد كه متغيرهاى راهبردهاى كنار آمدن در رابطه حساسيت اضطرابى، سو گيرى شناختى كو دك،، و & 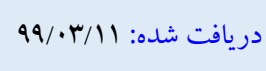 \\
\hline باورهاى مادر با اضطراب كود كى، نقش مهمى دارند؛ بنابراين آموزش هاى شناختى به مادر و كود كك و در نتيجه بهبود راهبردهاى كنار آمدن & 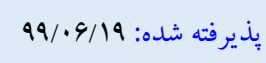 \\
\hline كودك، مىتواند در كاهش اضطراب كودكك بسيار مؤثر باشد. & منتشر شده: 99/9/IV \\
\hline
\end{tabular}

* نويسنده مسئول: حميد يورشريفى، دانشيار گروه روانشناسى، دانشكده روان شناسى، دانشكاه علوم بهزيستى و توانبخى تهران، ايران. رايانامه: Poursharifih@gmail.com 
ديخر مشخص شد كه حساسيت اضطر ابى به عنوان يكك ويزگى صفتى بر اضطراب كود كان تأثير دارد (r) . (I) .

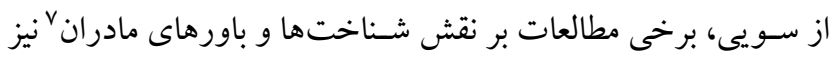

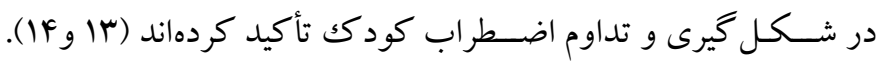
مادران كود كان مضطرب، شر ايط مبهم را به صورت يكك تهديد ارزيابى لدوم

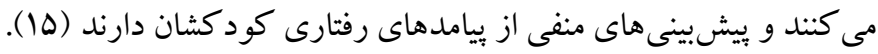

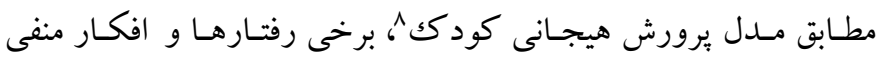

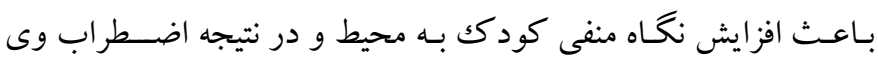
مىشـود (1) (IV ). در همين راسـتا، مقدميور و ســـهوند (IN) نيز بيان

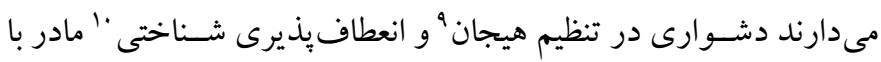

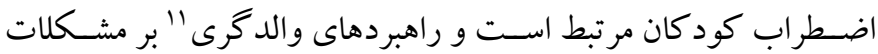

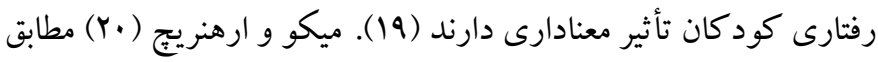

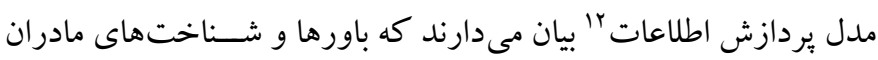

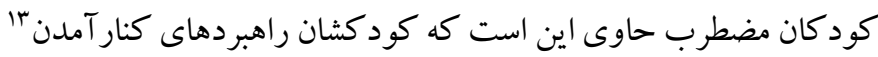
مناسب و كافى را بر ایى مو اجهه با اضطر اب ندارند و معتقدند اين كود كان

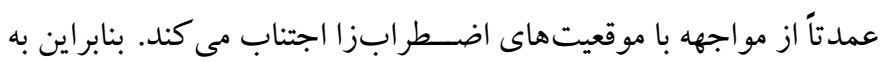

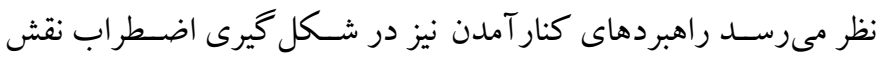

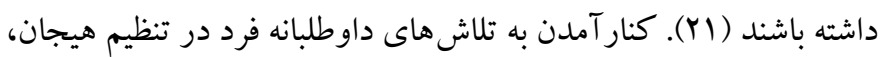

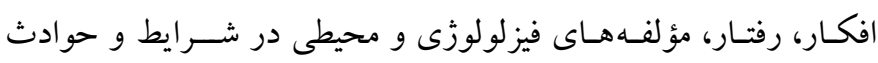

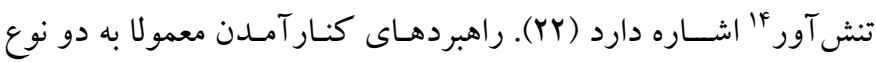

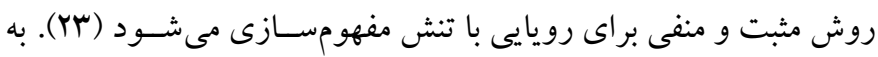

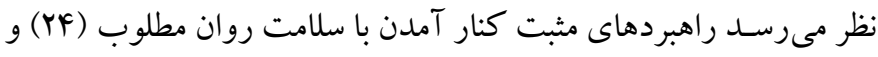

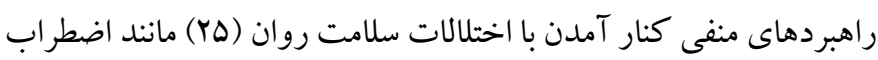

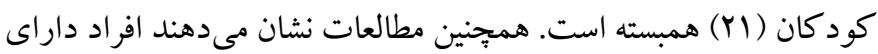

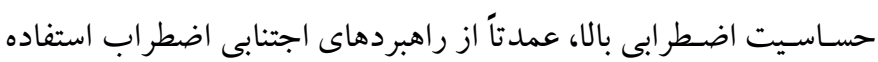
مى كنند ( •او و (Y). وران و كاكس (YV) معتقدند بين سـبك كنار آمدن

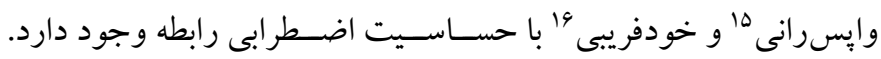

9. Emotion regulation

10. Cognitive flexibility

11. Parenting style

12. Information processing model

13. Coping strategies

14. Sterssing

15. Repressive

16. Self-deceptive
مقدمه

اضطراب 'داراى عاطفه منفى اسـت و يكك احسـاس نخرانى در مورد

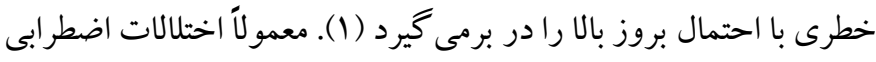

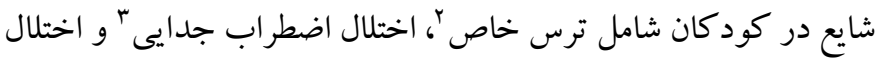

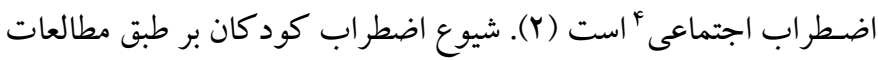

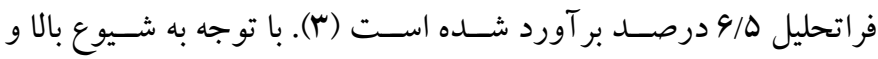
ييامدهاى اضطر اب در كود كان، شناسايى عوامل ايجاد كننده آن ضرورى

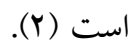

به نظر مىرســــ مفاهيم شــناختى در بروز اختلالات اضـطر ابى نقش عمده دارند (F). يكى از مؤلفه هاى شناختى مر تبط با اضطر اب كود كان،

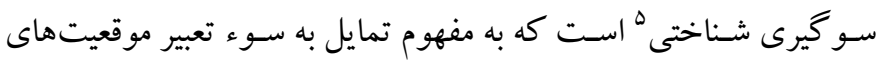

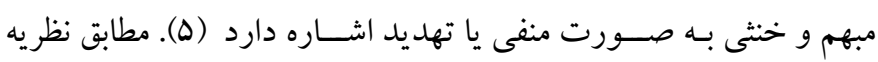

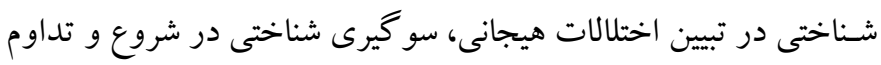

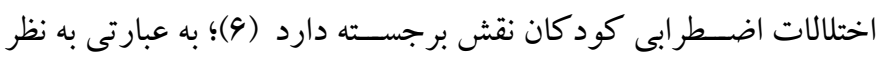
مىرسـد كود كان مضطرب بيشتر تمايل به سوء تعبير موقعيت هاى مبهم

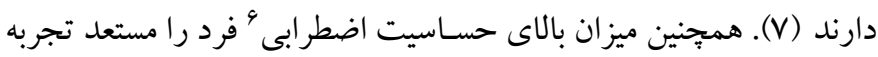

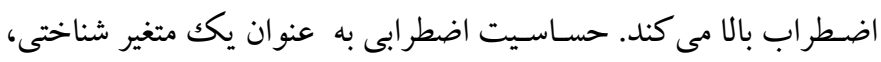
نشـاندهنده تفاوتهاى فردى اسـت كه به وسـيله ترس از احســاسـات

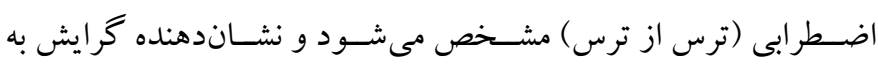
فاجعهنمايى در رابطه با بيامدهاى خنين احساس هايى است (^). حساسيت

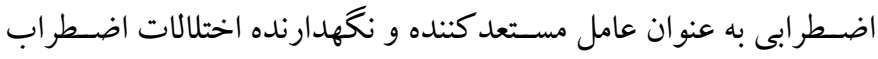

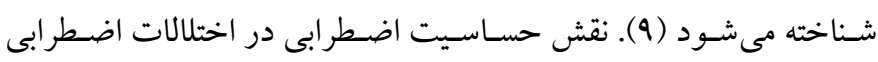

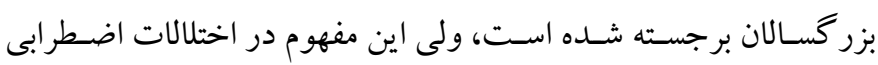
كود كـان، كمتر مورد توجـه واقع شــده اســت ( •(1). براى مثـال نتايج يُزوهش آندرسون و هوب (11) نشان داند كه نوجو انان مبتلا به اضطراب اجتماعى در مقايسه با همتايان فاقد اضطراب از حساسيت اضطر ابى و و برانخيختخى روانشـناختى بيشترى رنج مىبرند. همجنين در يكك مطالعه

1. Aanxiety

2. Specific phobia

3. General anxiety disorder

4. Social anxiety disorder

5. Cognitive bias

6. Anxiety sensitivity

7. Maternal beliefs

8. Child rearing emotional model 
كنار آمدن در بيشبينى اضطر اب كود كان تأييد شـده اسـت، ولى سـهم

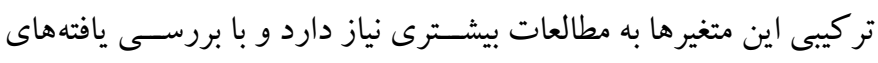

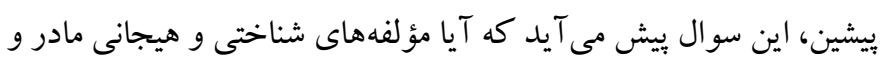

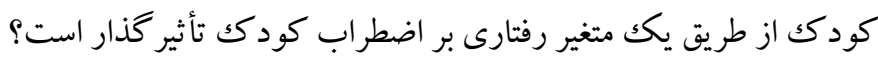
بنابر اين بر مبناى بيشـينه يزوهشـى عنوان شـــه، مطالعه حاضــر به دنبال

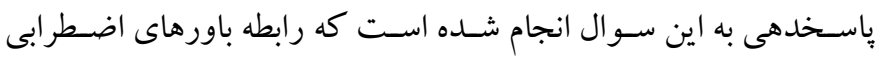

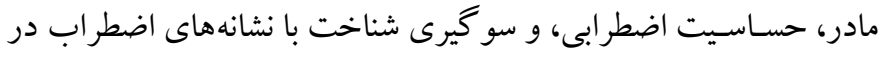

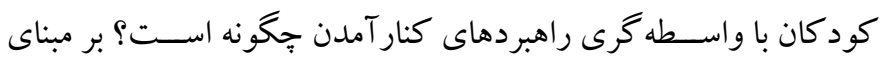
توصسيفات ارائه شـده، يزووهش حاضـر سعى دارد مدل بيشـنهادى زير را مورد بررسى قرار دهد.
كوييكك و منصـور (YN) بيان مىدارند افرادى كه حســــيت اضـطر ابى باليى دارند، وقتى از راهبردهاى كنار آمدن منفى اسـتفاده مى كنند، فشار

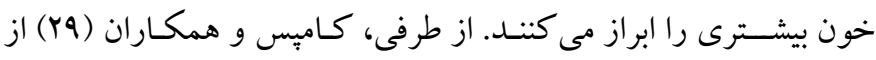

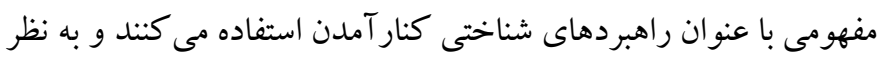
مىرســ اين راهبرد در شـروع و تداوم اختلالات اضـطر اب نقش داشـته

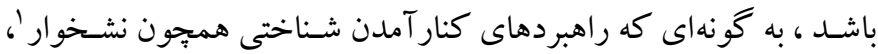

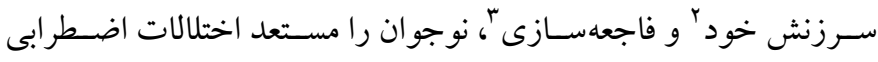

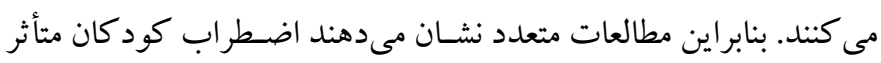

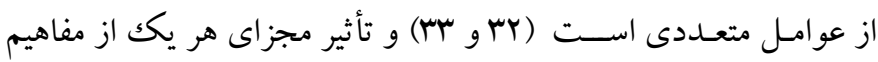

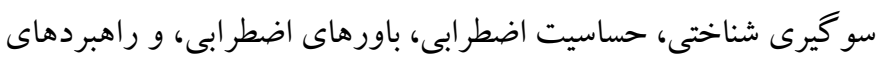

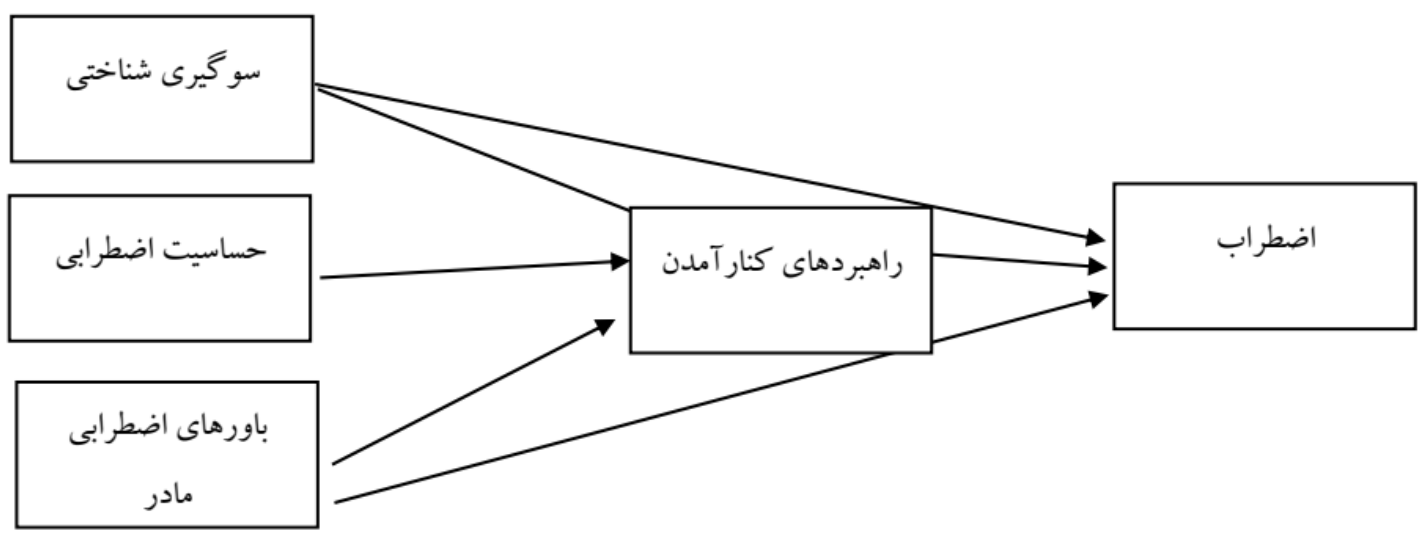

شكل 1: مدل ييشنهادى نشانهاى اضطراب كودكى

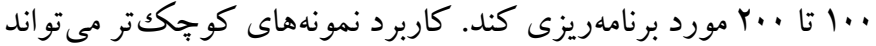

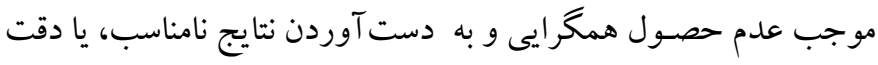

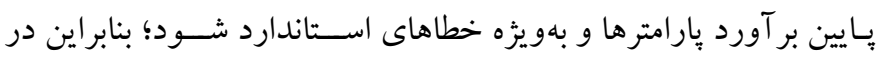

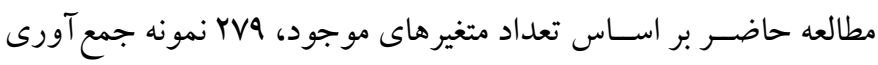

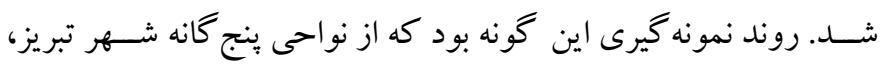

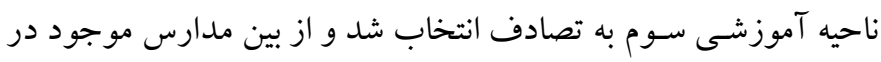

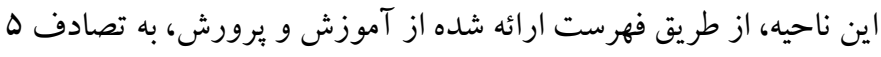

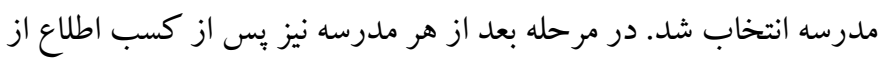

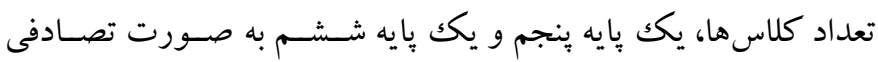

\section{Catastrophizing}

1. Rumination

\section{Self-blame} الف) طرح هزوهش و شر كت كنند كان: مطالعه حاضر از نوع توصيفى

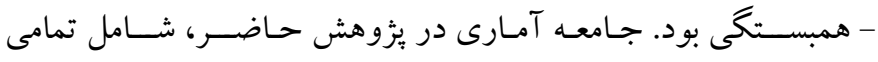
دانش آموزان Iال الى Y | سـاله مدارس غيردولتى (يايه ينجم و شـشم) در

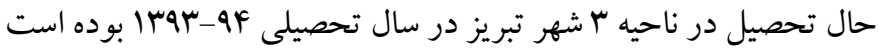

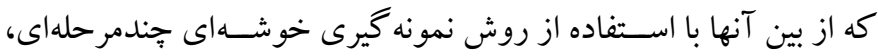

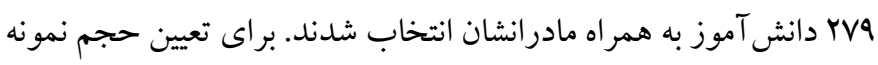

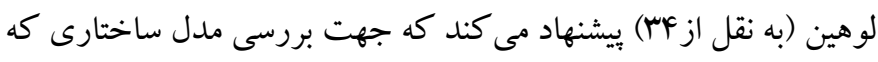

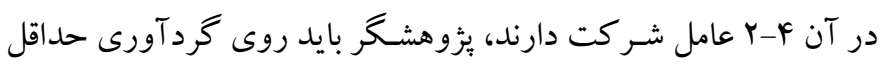


همسـى براى كل مقياس AF/ • و براى خردهمقياسها بين rه/ • تا FA/ .

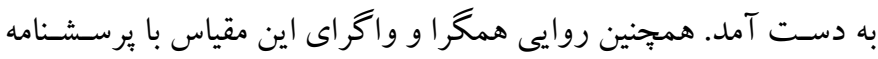

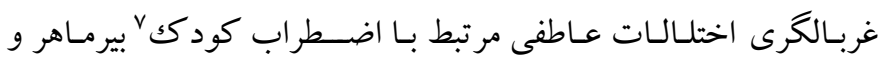

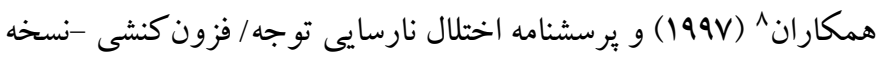

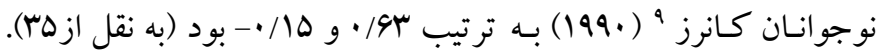

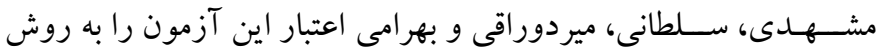

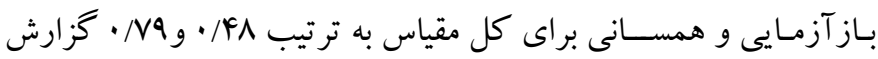

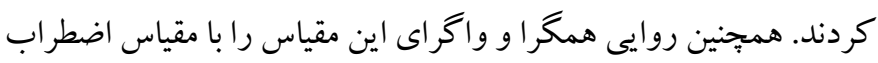

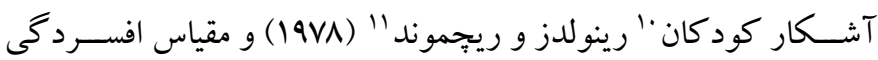

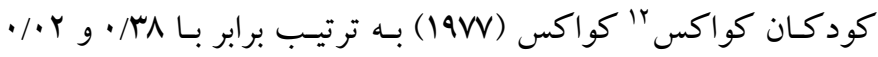

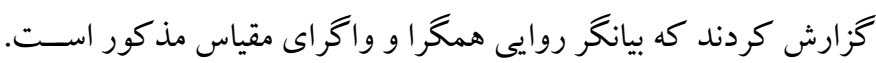

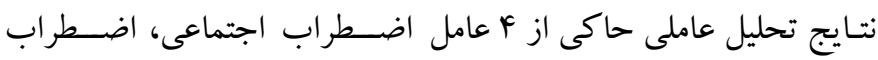

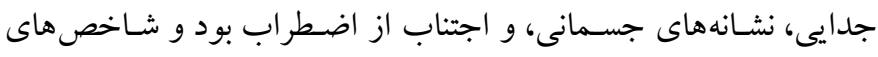

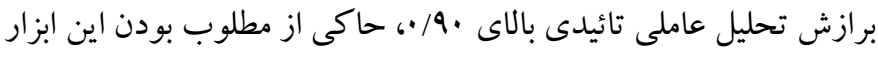

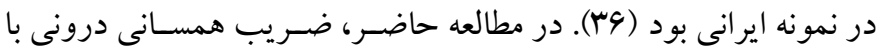

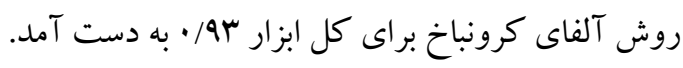

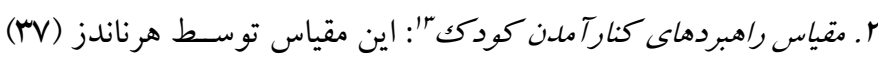

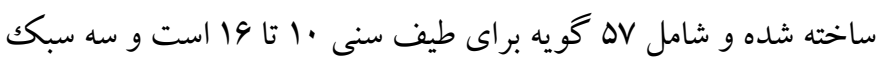

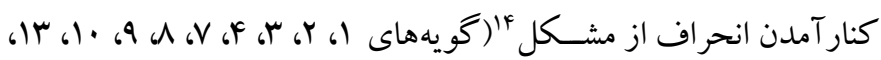

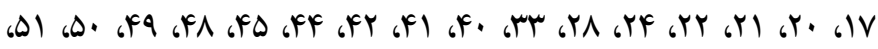

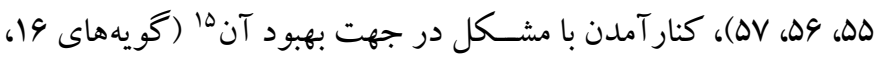

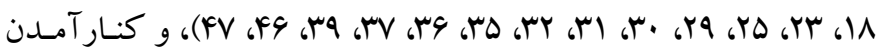

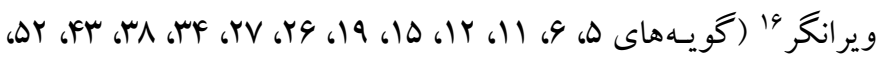

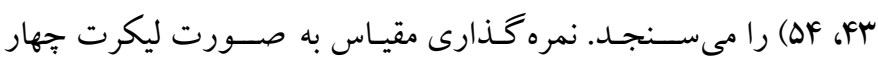

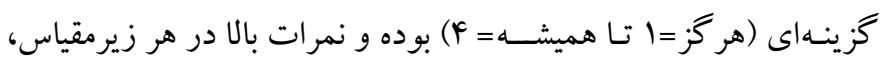

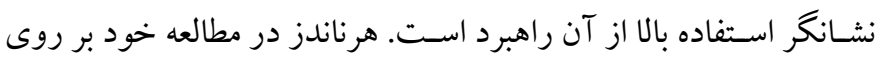

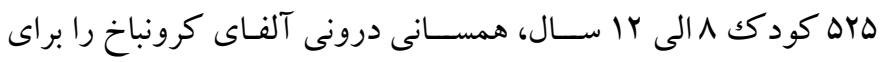

9. The Conners' attention deficit hyperactivity disorder-adolescent version

10. Children,s manifest anxiety scale

11. Reynolds \& Richmond

12. children depression scale, Kovacs

13. Children's coping behavior questionnaire (CCBQ)

14. Divertion coping

15. Coping ameliorative

16 . Destructive coping
انتخـاب شــدنـد، و در گام نهايى يرسـشـــامه مورد نظر در اختيار تمام دانش آموزان منتخب، قرار داده شــــ. ملاككهاى ورود به مطالعه شــامل

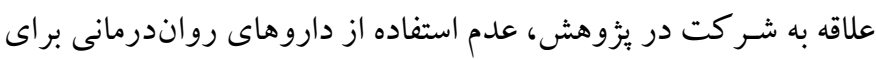
كودك و مادر در زمان مطالعه، تحصيلات بالاى راهنمايى مادران، در قيد

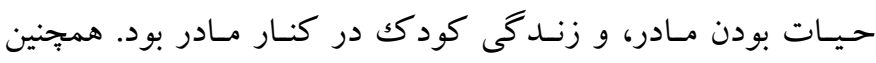
ملاككهاى خروج شـامل تكميل ناقص برسشنامه، سطح تحصيلات كمتر

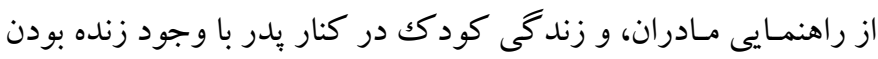

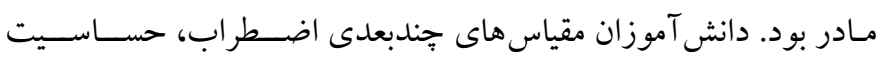

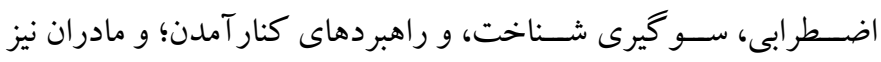

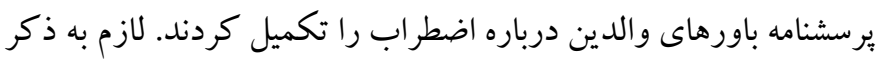

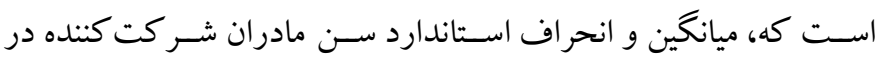

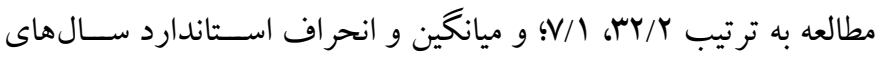

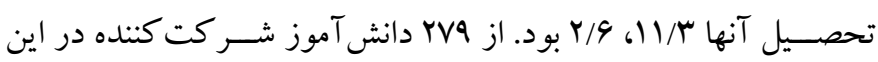

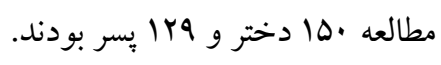

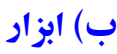

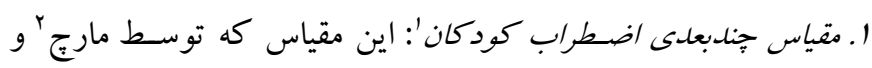

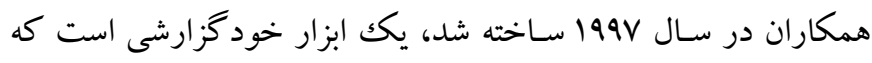

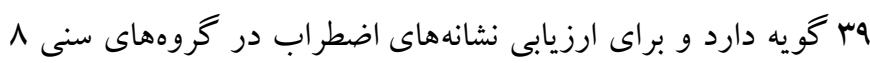

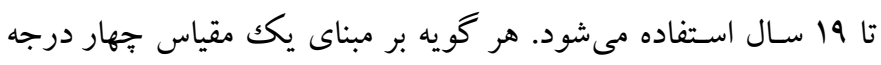

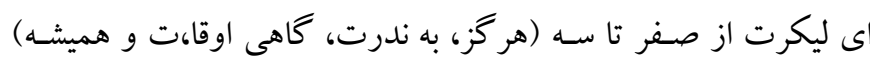

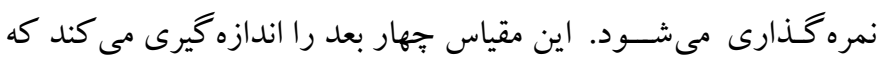

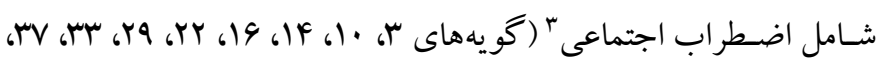

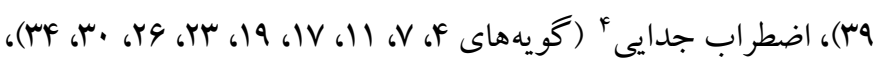

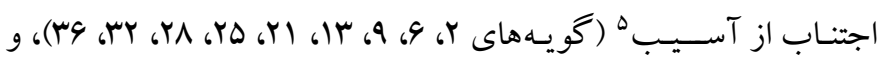

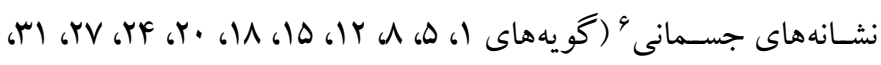

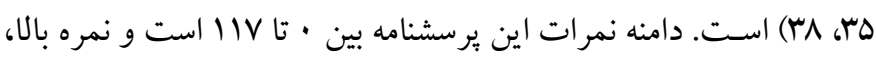

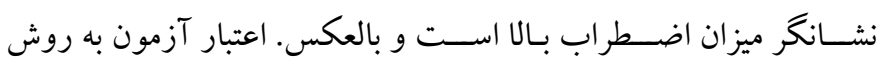

1. Multidimensional anxiety scale

2. March

3. Social anxiety

4. Separation anxiety

5. Harm aviodance

6. Physical symptoms

7. The Screen for child anxiety related Emotional Disorders 8. Birmaher 


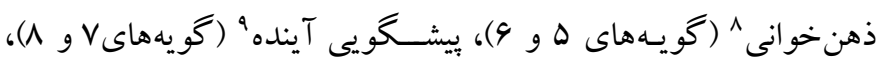

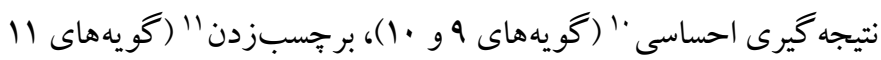

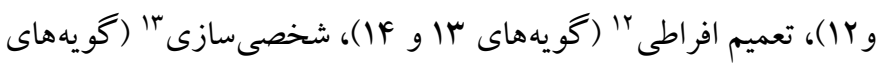

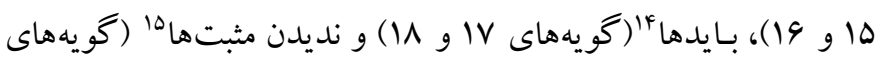

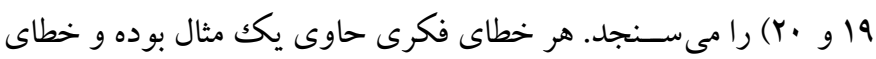

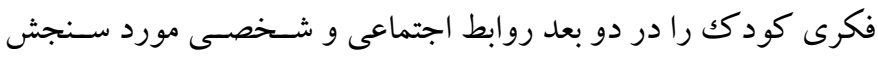

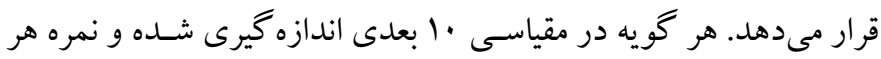

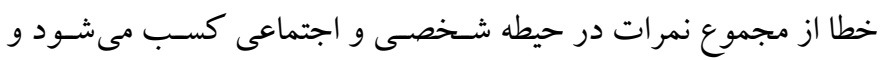

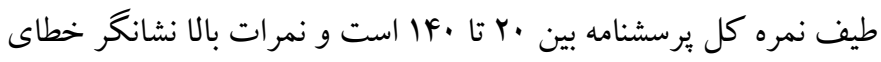

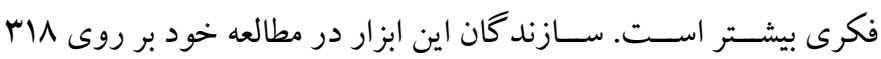

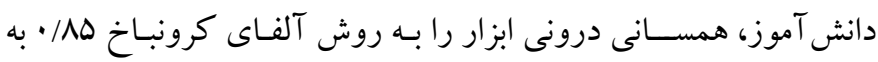

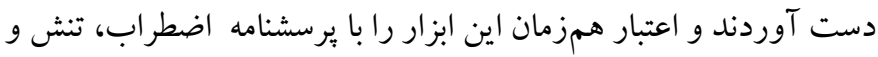

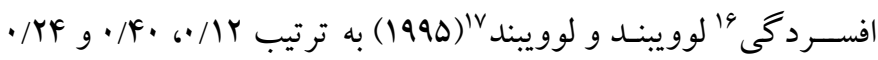

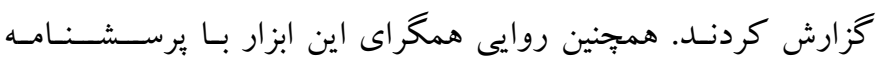

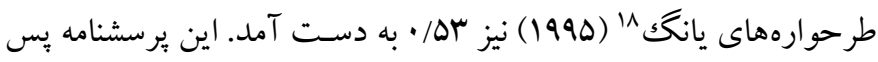

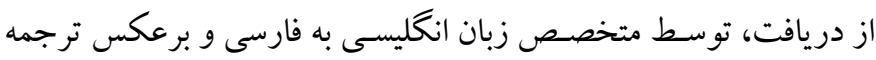

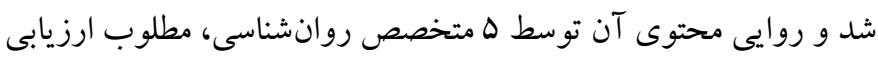

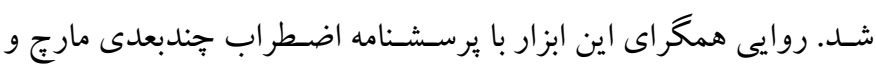

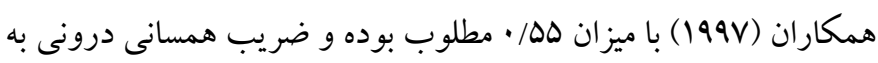

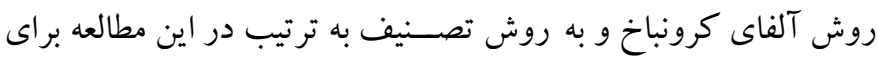

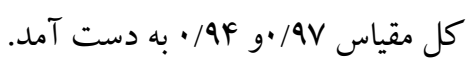
f. مقياس حساسـيت اضطرابى كودكى": مقياس حساسيت اضطر ابى توسط

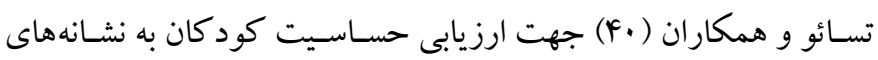

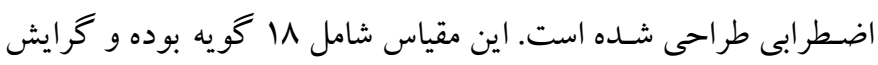
بدنى و شـناختى فرد را به موقعيتهاى خطر ناك ارزيابى مى كند. مقياس

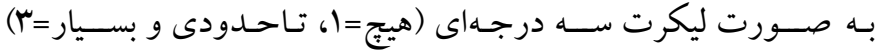

11. Labeling

12. Overgeneralization

13. Personalization

14. Should statements

15. Minimizing the positive

16. Depression anxiety stress scales

17. Lovibond \& Lovibond

18. Young schema questionnaire

19. Child anxiety sensitivity scale
انحراف از مشـكـل سو/•، كنـار آمــن در جهـت بهبود آن M/ •، و

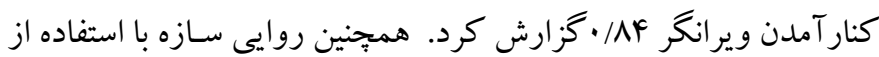
محاسـبه همبسـتِى بين سـه عامل اين برســــامه با نمرههاى اضطر اب و افسـردخى يرسـشـنامه سـيسـتم ارزيابى رفتار براى كود كان نسـخه دوم'

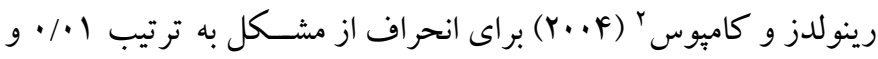

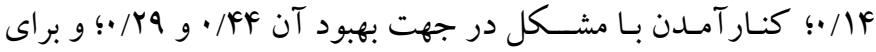
كنار آمدن ويرانكر ه / • و • • • • بر آورد شد. همجنين روايى صورى اين ابزار با ارزيابى متخصـصـان قابل قبول گزارش شـد. لازم به ذكر است در مطالعه بر روى نمونه ايرانى، نتايج مربوط به شــاخص هاى برازش تحليل

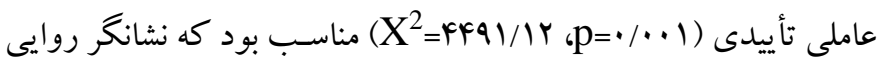
مناسب يرسشنامه است. روايى همخر ايى يرسشنامه، ار تباط رضايتبخش بين نمره كل ابعاد را نشـان داد. براى بررسسى روايى همزمان، همبسـتِى

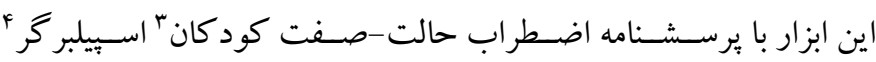

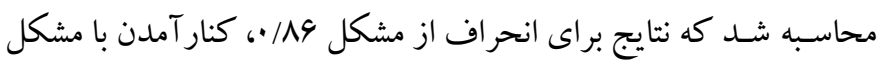

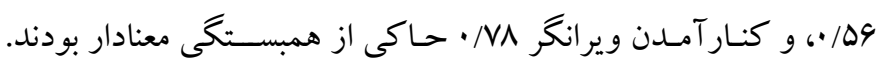
همسانى درونى به روش آلفاى كرونباخ بين I/ • تا FF/ • و روش آزمون مجدد بعد از دو هفته براى انحراف از مشــكل، كنار آمدن با مشـكل، و و

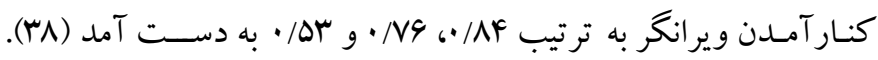
ميزان همسـانى درونى به روش آلفاى كرونباخ مقياس در مطالعه حاضـر روى TVq دانسش آمـوز، بـراى زيرمقيـاس انحراف از مشـكـل

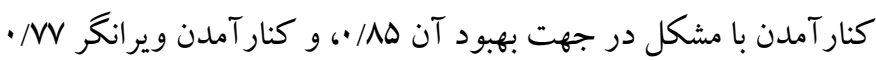
به دست آمد.

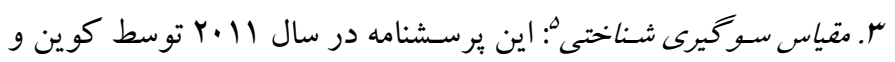

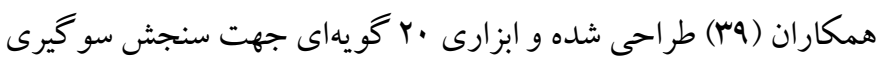
شناختى كود كان و نوجوانان 11-19 سال است و • ا خطاى فكرى تفكر

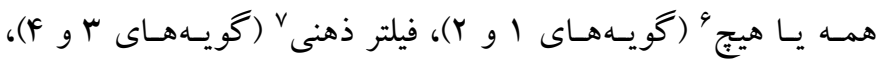

1. Behavioral Assessment System for Children, Second Edition

2. Reynolds \& Kamphaus

3. State-trait anxiety children inventory

4. Spielberger

5. Cognitive distortions scale

6. All-or-nothing thinking

7. Mental Filter

8. Mind reading

9. Catastrophizing

10. Emotional reasoning 


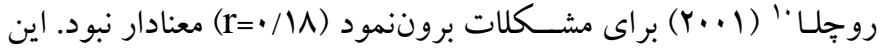

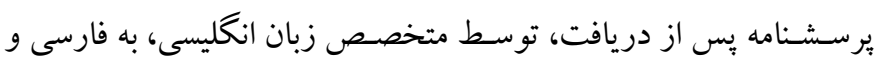

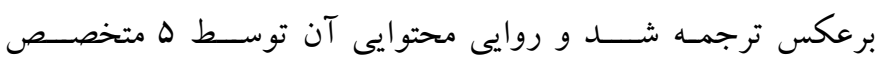

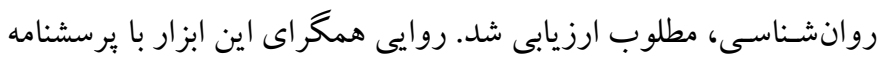
اضطر اب جندبعدى مارج و همكاران (199V) و يرسـشــنامه حسـاسـيت

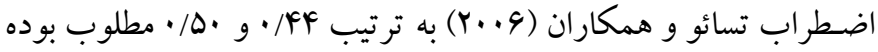

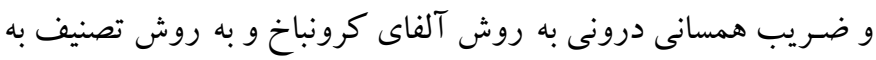

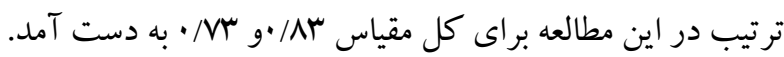

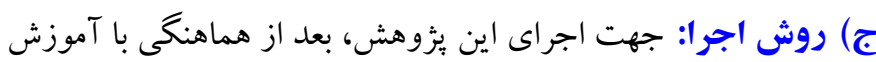

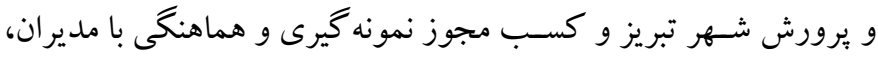

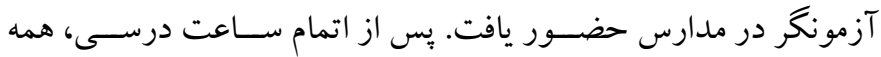

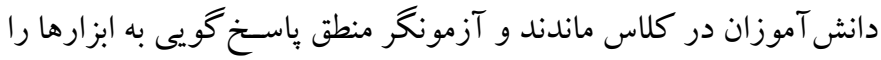

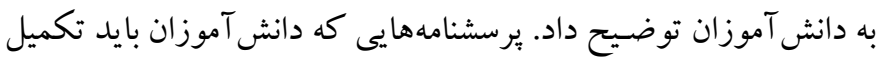

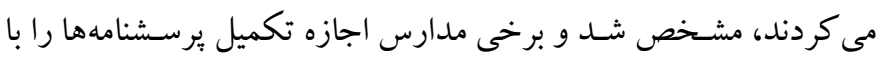

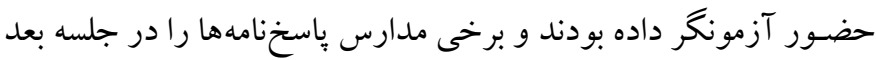
تحويل دادند. همجنين برسـشــنامه والدين نيز جهت تكميل در اختيار

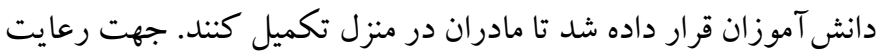

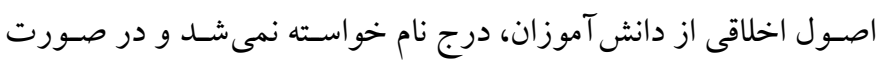

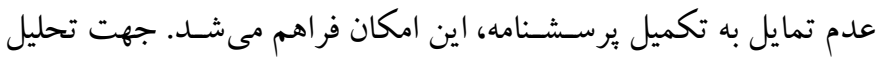

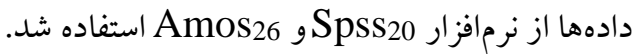

\section{يافته ها}

در جدول ا شـاخص هاى توصسيفى متغيرهاى بثزوهش شــامل ميانخين،

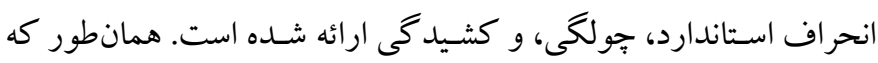
ملاحظه مىشود قدر مطلق جولكى و كشيد گى تمام متغيرها مطابق الكوى

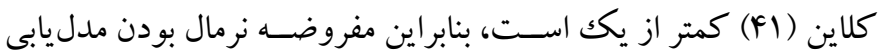

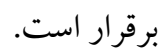

6. Parental beliefs about anxiety questionnaire

7. Revised child anxiety and depression scale

8. Chorpita

9. Child behavior checklist

10. Achenbach and rescorla
نمره گذارى شـــه و يكك نمره كلى از حسـاسـيت اضـطر ابى به دسـت

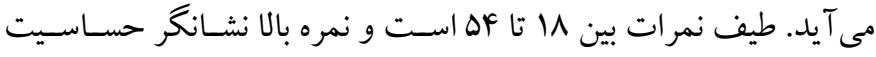

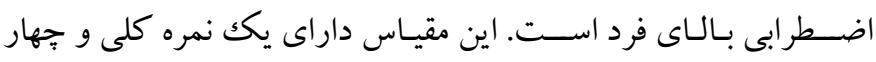

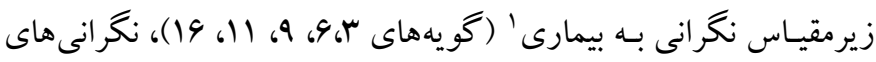

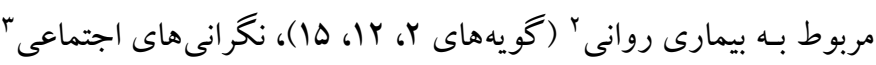

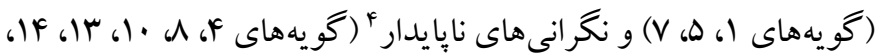

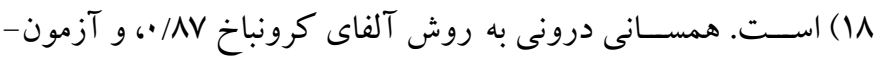

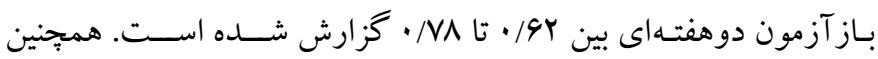

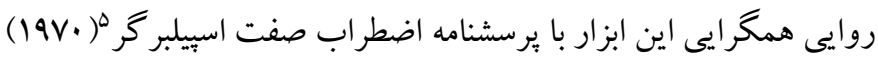

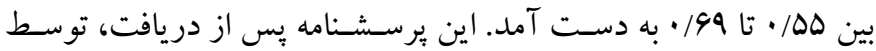

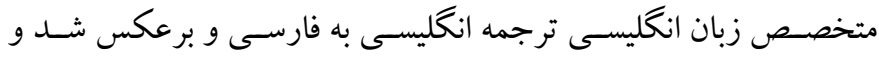

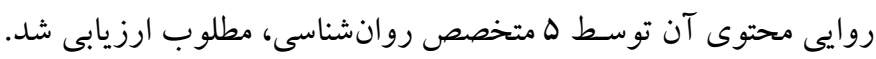

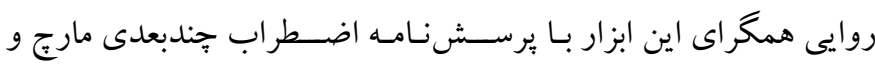

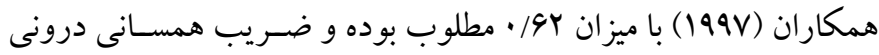
بهروش آلفاى كرونباخ و به روش تصـنيف به ترتيب در اين مطالعه براى

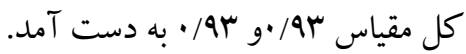

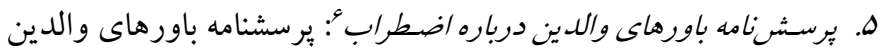

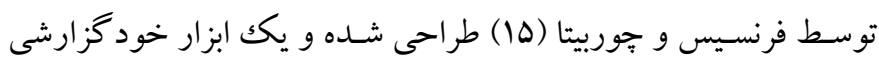

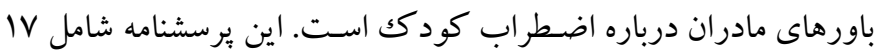

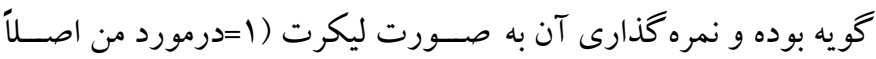

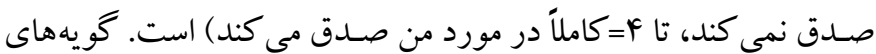
9 و Fا به طور معكوس نمره كذارى مىشـوند و طيف نمرات بين · تا 91

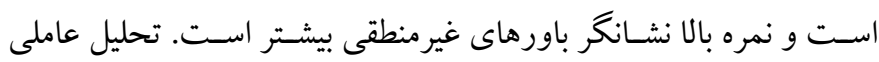

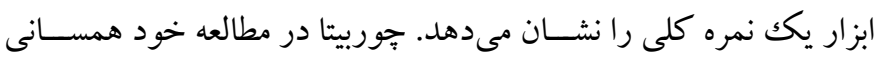

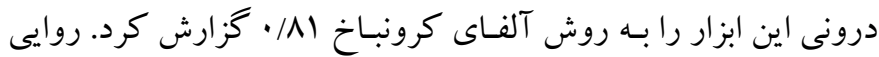

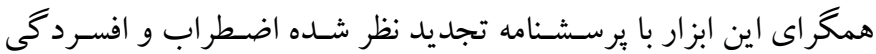

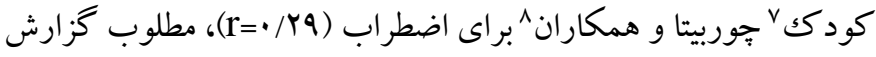

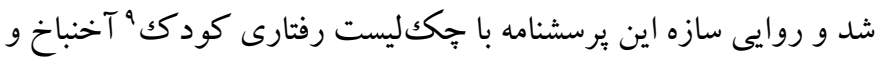

1. Disease concerns

2. Mental illness concerns

3 . Social concerns

4. Unsteady concerns

5. Spielberger trait anxiety inventory 
جدول 1: شاخصهاى توصيفى متغيرهاى ئوهش

\begin{tabular}{|c|c|c|c|c|}
\hline كشيدىى & جولَى & انحر اف معيار & ميانغين & \\
\hline-1 &.$/ 1$ & $9 / 1 Y$ & 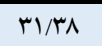 & حساسيت اضطر ابى \\
\hline$-\cdot / \Delta$ & $\cdot / 4$ & $r V / 9$ & $q \pi / V V$ & سو گيرى شناختى \\
\hline$-\cdot / \cdot \Delta$ & $\cdot /$ & $9 / \cdot \Delta$ & $F I / V$ & 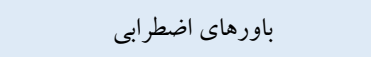 \\
\hline$-\cdot / V$ & $-\cdot / r$ & IN/AF & VG/9Y & انحر اف از مشكل \\
\hline$-\cdot / 4$ & $\cdot / r$ & $\Delta / 9$ & $m / v i$ & كنار آمدن وير انخر \\
\hline$\cdot 19$ & $-\cdot / 9$ & $\Lambda / \cdot 4$ & $\mathrm{Mr} / 9 \mathrm{Y}$ & كنار آمدن با مشكل در جهت بهبود آن \\
\hline$\cdot 19$ & $-\cdot / 1$ & $r \cdot / V^{F}$ & $9 N / \cdot 1$ & اضطراب \\
\hline
\end{tabular}

راهبرد كنار آمدن با مشـكل در جهت بهبود آن (194/•-) با اضـطراب، منفى بوده و در سـطح آلفاى I • • معنادار اسـت. همبسـتخى بين راهبرد كنار آمدن وير انكر (F) • • با اضطراب در سطح هـ • • معنادار نيست.
در جدول r ماتريس همبستخى متغيرهاى يثزوهش ارائه شده است. بر اسـاس نتايج به دست آمده ضـرايب همبستِكى بين حسـاسيت اضطر ابى

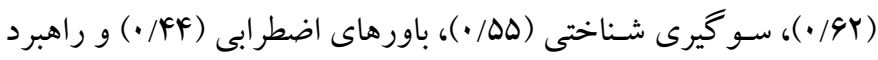
انحراف از مشـكل (ه9/•) با اضطر اب، مثبت؛ و ضـريب همبستِكى بين

جدول r: ماتريس همبستغى متغيرهاى يزوهش

\begin{tabular}{|c|c|c|c|c|c|c|c|}
\hline r & 7 & 0 & $\varepsilon$ & $r$ & $r$ & 1 & \\
\hline & & & & & & 1 & 1. ساسيت اضطرابى \\
\hline & & & & & 1 & $.1944 * *$ & r. سو گيرى شناختى \\
\hline & & & & 1 & $\cdot / 011 * *$ & $-\cdot / \Delta \cdot \wedge * *$ & r.r. باورهاى اضطر ابى \\
\hline & & & 1 & - /FFF** & . /DFY** & $\cdot / \Delta 9 \uparrow * *$ & F. أنحراف از مشكل \\
\hline & & 1 & $\cdot / \wedge ґ * *$ &.$- / . q F$ & $\cdot / \cdot \mathrm{va}$ & $\cdot / / 9 V^{* *}$ & هـ كنار آمدن ويرانگر \\
\hline & 1 &.$- / .49$ &.$- / 941 * *$ & $-\cdot / \& \wedge 9 * *$ & $-\cdot / \Delta M \Lambda_{* *}$ & $-\cdot / 949 * *$ & 9. كنار آمدن با مشكل در جهت بهبود آن \\
\hline 1 & $-\cdot 1994 * *$ & .1 .44 & $\cdot / \Delta q \uparrow * *$ & $\cdot / 4 F \wedge * *$ & $\cdot / \Delta \Delta Y * *$ &.$/ 9 Y \Delta * *$ & V. اضطراب \\
\hline
\end{tabular}

كمتر از ب قابل بذيرش است؛ شاخص نيكويى برازش ' (GFI)، شاخص برازش تطبيقى ' (CFI) كه مقادير بيش از ه/ • نشـانگر برازش مناســب الكو اســت؛ شـاخص نيكويى برازش تعديل يافته ' (AGFI) كه مقادير بيشتر از ^/ • قابل قبول است، شاخص برازش ايجاز م (PNFI) كه مقادير بيشـتر از 9/ • نشـانكر برازش مناسـب الكوى هسـتند؛ و مجذور ميانكين مربعات خطاى تقريبه (RMSEA) كه مقادير كمتر از ^•• • نشـانخر برازش مناسب الكو هستند. در جدول باين شاخص ها گزارش شدهاند.

4. Parsimony fit index

5 . Root mean square error of approximation
روش بيشينه احتمال براى آزمون الكوى نظرى يثروهش و برازش آن

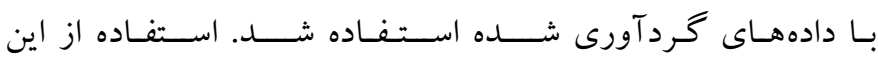
روش نيـازمنــ نرمـال بودن جنــدمتغيره متغيرها اســـت. در يثزوهش براى بررسى نرمال بودن جندمتغيره از ضـريب كشيدكى استاندارد شده مرديا استفاده شد. اين عدد در يزوهش حاضر 14/1/19 به دست آمد كه كمتر از عدد سواست كه از طريق فرمول (p+2) محاسبه شده است. در اين فرمول p مساوى با تعداد متغيرهاى مشاهده شده است كه در اين يثوهش است. براى بررسى برازش مدل از شاخص هاى گيفن و همكار ان (FY) استفاده شـد. اين شـاخصها شـامل اين موارد بودند: X2/df كه مقادير

1. Goodness of fit index

2. Comparative fit index

3 . Adjusted goodness of fit index 
هستيند. مقادير RMSEA و R2/d.f نيز كمتر از مقادير ذكر شــده در

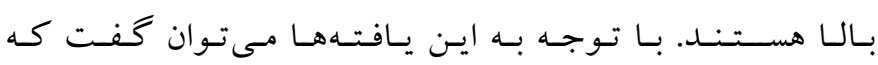

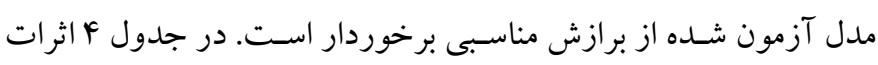

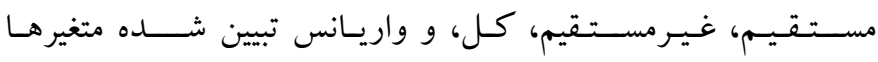
كزارش شده است.
جدول r: شاخصهاى نيكويى برازش الكوهاى آزمون شده بزوهش

\begin{tabular}{cccccc}
\hline RESEA & PNFI & AGFI & CFI & GFI & X2/df \\
\hline .1 .99 &.$/ 90$ &.$/ 91$ &.$/ 9 \Delta$ & $\cdot / 94$ & $r / \Lambda r 1$ \\
\hline
\end{tabular}

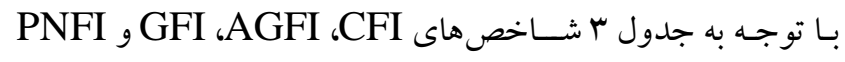

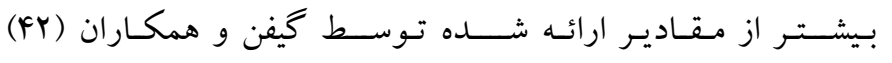

\begin{tabular}{|c|c|c|c|c|c|}
\hline واريانس تبيين شده & اثر كل & اثر غيرمستقيم & اثر مستقيم & به متغير & از متغير \\
\hline & $\cdot / \mathbb{V} 9 * *$ & - & $\cdot / \pi \vee 9 * *$ & & حساسيت اضطرابى \\
\hline \multirow[t]{3}{*}{$\cdot / 4}$. & $\cdot / r \cdot \Delta * *$ & - & $\cdot / r \cdot \Delta * *$ & \multirow[t]{3}{*}{ انحراف از مشكل } & سو كيرى شناختى \\
\hline & $\cdot / 14 \lambda * *$ & - & $\cdot / / F \wedge * *$ & & باورهاى اضطرابى \\
\hline & $\cdot / r \Delta q * *$ & - & $\cdot / r \Delta 9 * *$ & & حساسيت اضطرابى \\
\hline \multirow[t]{3}{*}{.1 .91} &.$- / \% \mu$ & - &.$- / .4 r$ & \multirow[t]{2}{*}{ كنار آمدن ويرانغر } & سو گيرى شناختى \\
\hline & $-\cdot / r \Delta r * *$ & - & $-\cdot /$ rar** & & باورهاى اضطرابى \\
\hline & $-\cdot / 4 \mid \uparrow * *$ & - & $-\cdot /\{\mid \uparrow * *$ & \multirow{3}{*}{ كنار آمدن با مشكل در جهت بهبود } & حساسيت اضطرابى \\
\hline \multirow[t]{5}{*}{.$/ \mathrm{FWV}$} & -•/r|r** & - & $-\cdot / r \mid r * *$ & & سو گيرى شناختى \\
\hline & $-\cdot / 199 * *$ & - &.$- / 199 * *$ & & باورهاى اضطرابى \\
\hline & $\cdot / 441 * *$ &.$/ 190^{*}$ & . /rrg** & \multirow{6}{*}{ اضطراب } & حساسيت اضطرابى \\
\hline & $\cdot / 19 \cdot * *$ &.$/ 110^{*}$ & $\cdot / \cdot v \Delta$ & & سو گيرى شناختى \\
\hline & $\cdot / 1 T V^{*}$ & $\cdot / \ldots *$ & $\cdot / r v$ & & باورهاى اضطرابى \\
\hline \multirow[t]{3}{*}{$0 . \Delta Y 9$} & $\cdot / r \cdot V^{* *}$ & - & $\cdot / r \cdot V^{* *}$ & & انحراف از مشكل \\
\hline &.$- / . \Delta 9$ & - &.$- / . \Delta 9$ & & كنار آمدن ويرانخر \\
\hline & $-\cdot / r Y q * *$ & - & $-\cdot / r Y q * *$ & & كنار آمدن با مشكل در جهت بهبود \\
\hline
\end{tabular}

تأثير منفى دارد. حسـاسيت اضطر ابى هم به صسورت مسـتقيم

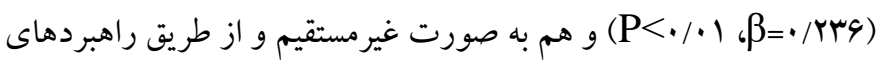

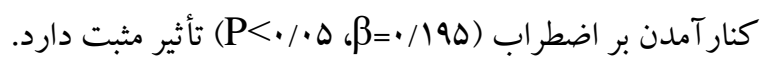
باورهاى اضطر ابى به صـورت مستقيم بر راهبرد انحر اف از مشـكل

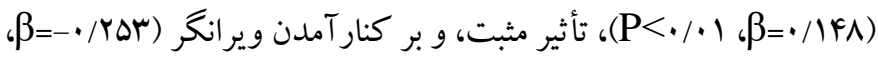

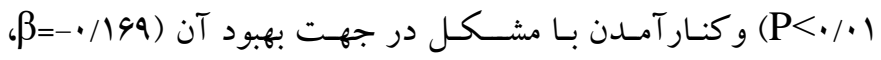

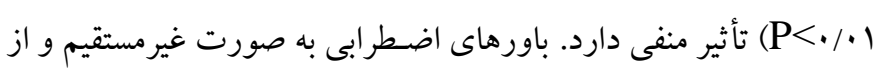

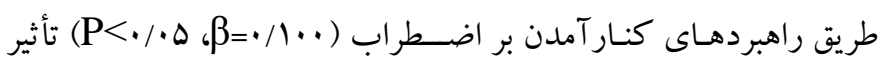
مثبت دارد. رابطه مستقيم بين باورهاى اضطر ابى مادر با اضطر اب معنادار

$$
\text { نيست (P> (P) (ه) }
$$

با توجه به اطلاعات مندرج و بر اسـاس نتايج تحليل مسير، سو گيرى

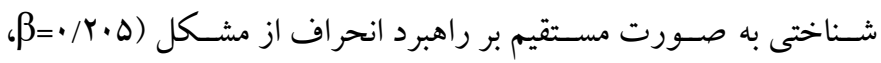

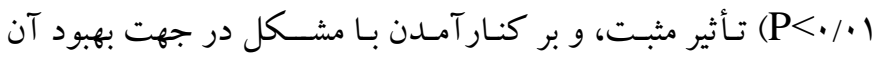

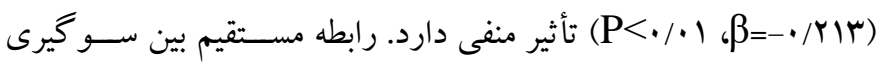

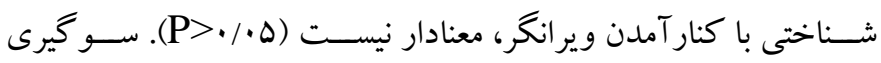

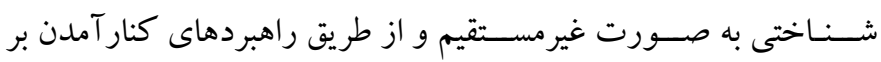

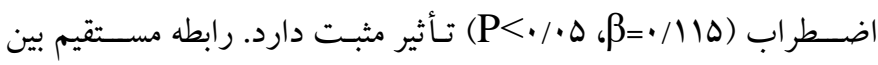

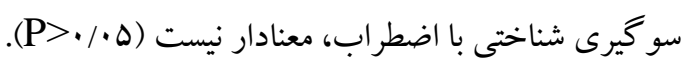
حسـاسيت اضطر ابى به صورت مستقيم بر راهبرد انحر اف از مشكل

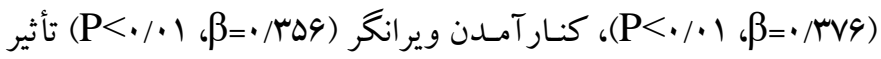

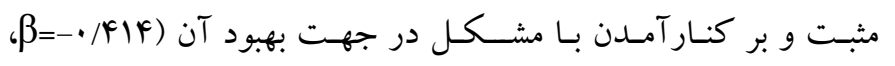


واريـانس كنـار آمـدن وير انخر، FV/V درصســ از واريـانس كنـار آمدن با

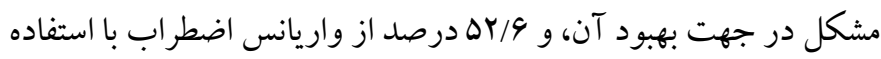

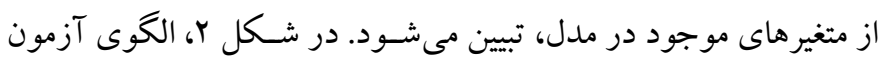
شده يُزوهش ترسيم شده است.

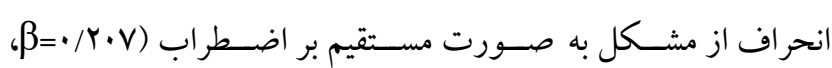

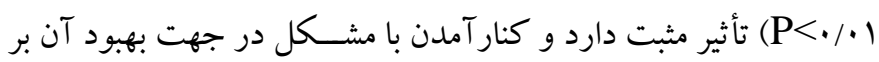

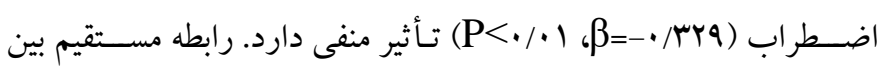

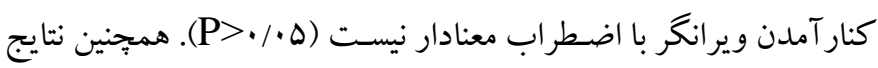

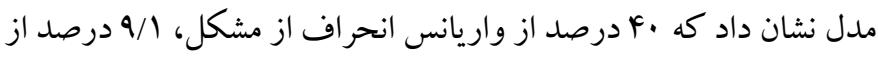

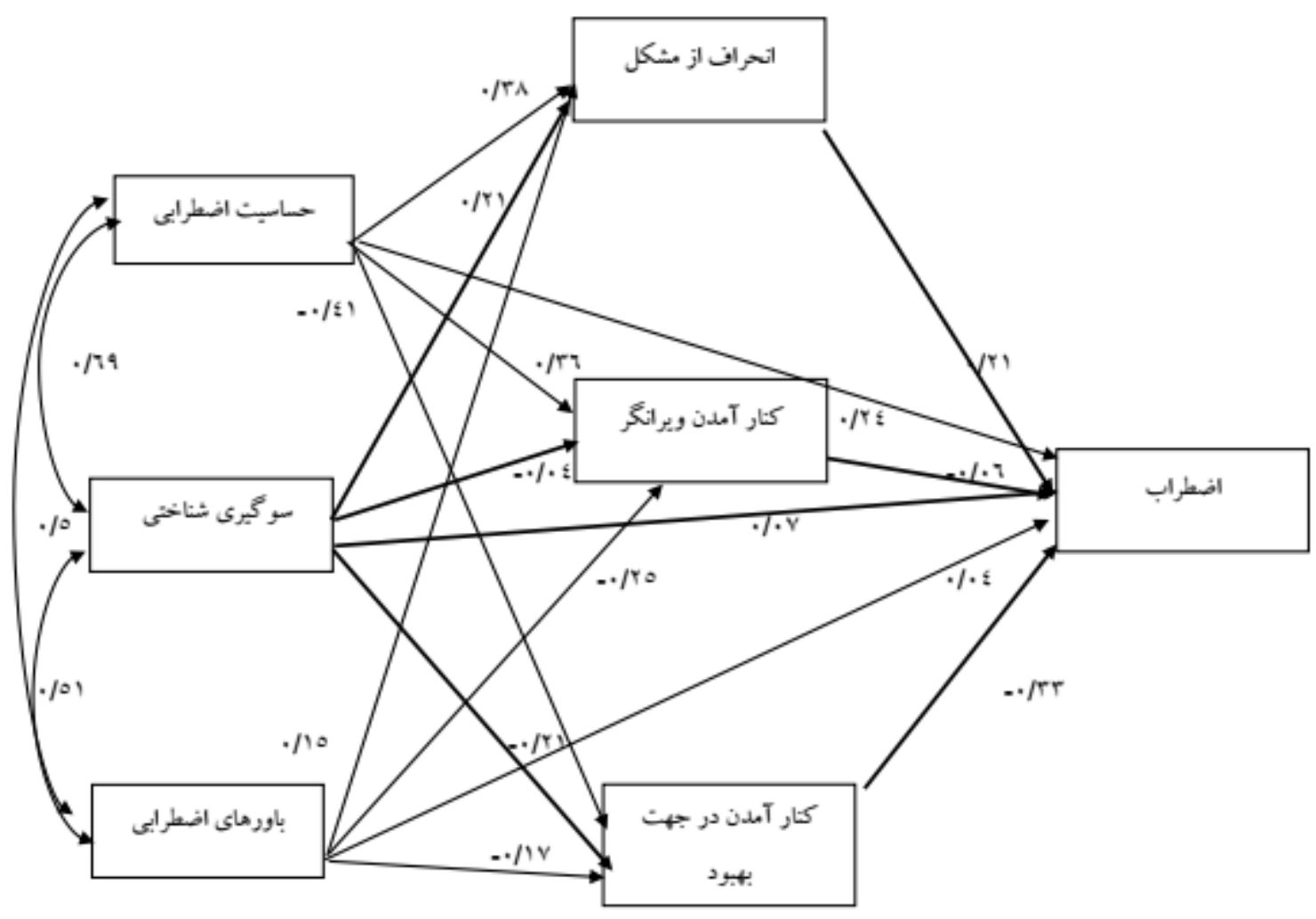

شكل r: الكوى آزمون شده يخوهش

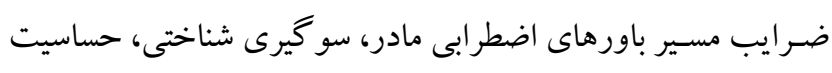

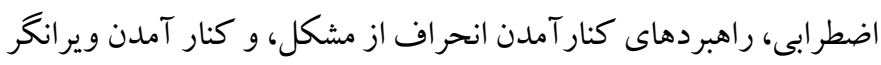
با نشـانههاى اضـطر اب نشــان مى دهد كه با افز ايش آنها بر نشــانه هاى

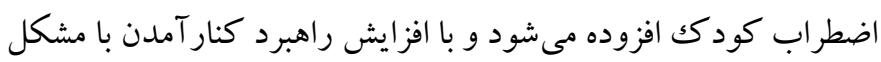

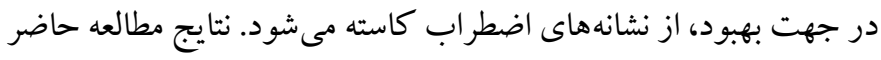

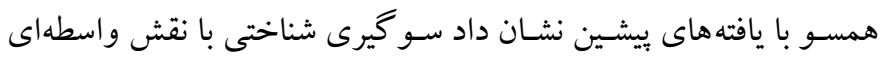

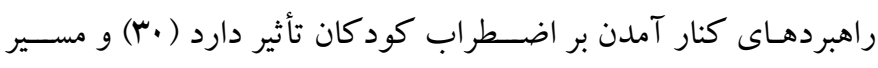
مستقيم سو گيرى شناختى با اضطر اب معنادار نيست و رابطه مستقيم بين

\section{بحث و نتيجه كيرى}

نتايج مطالعه حاضـر نشـان مىدهد كه مدل مدل به دســت آمده به منزله يك

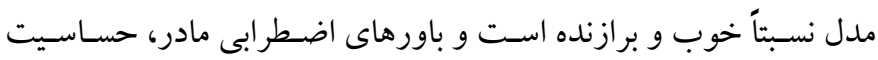

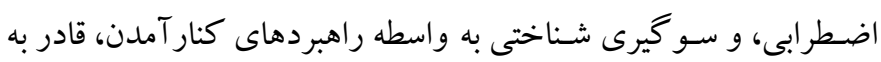
ييش بينى اضطراب كود كان هستند. مطابق يافتهاى ييينش، بين باورهاى

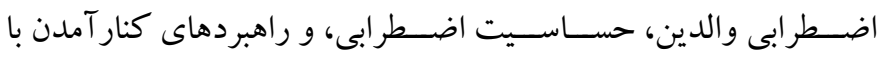
نشانهاى اضطراب كود كان رابطه وجود دارد (Y، ^و (Y) . 
همجِنين در تبيين نقش واسـطهاى راهبردهاى كنار آمدن، مىتوان به مفهوم اجتناب تجربهاى' توجه داشت. اجتناب تجربهاى نقش ميانجى بين

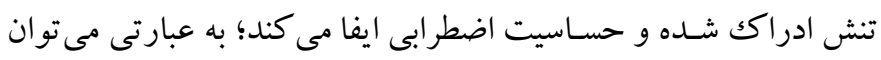

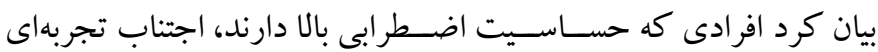

بيشترى و در نهايت تنش بيشترى را گزارش خواهند كرد (4 و و سب) .

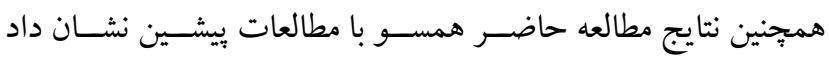

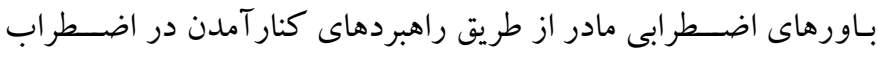

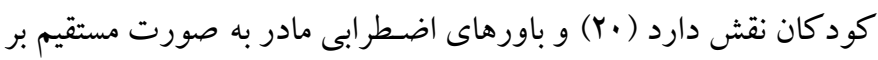

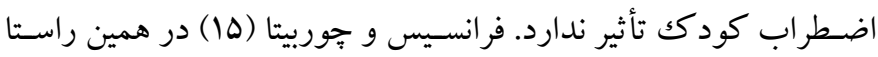
بيان مى كنند وقتى مادران باورهاى اضطر ابى بيشترى دارند، محر ككهاى

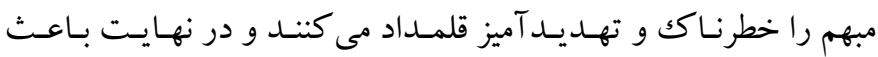
مىشـوند تا كود كشـان دنيا را به صسورت تهايد ارزيابى كند. همين باور

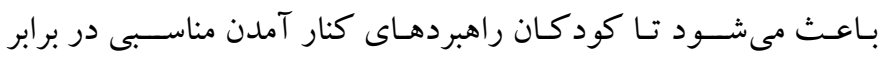

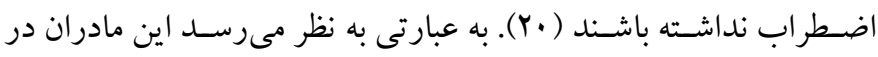

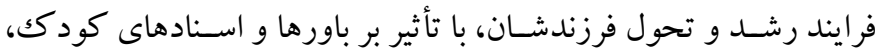
زمينه را براى افز ايش اضـطر اب فراهم مى كنند (19)؛ تا جايى كه مطابق

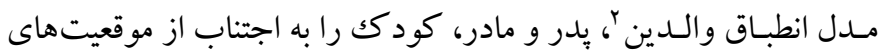

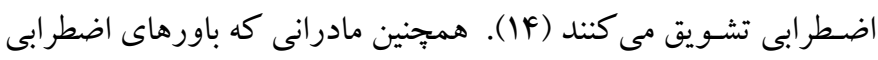
دارند و دنيا را به صسورت تهديد براى كودك خود مىبينند (N))، اين

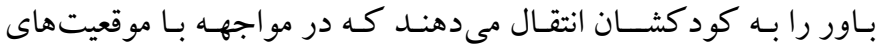
اضــر ابى، اجتناب و عدم حل مشــكل، راهحل مناســبى اســت. يافته

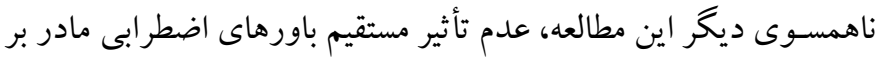

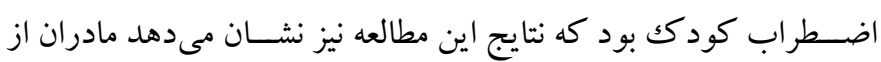

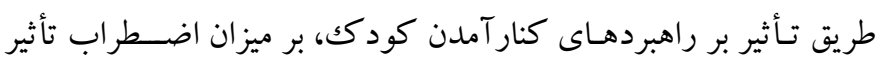

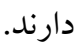

در نهايت نتايج مطالعه حاضـر نشـان داد سه مؤلفه شناختى و هيجانى

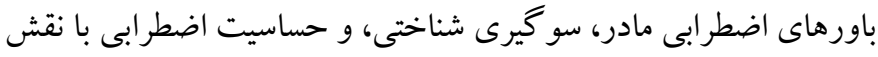

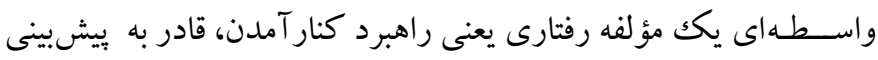

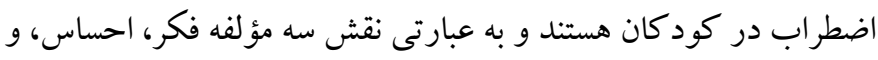

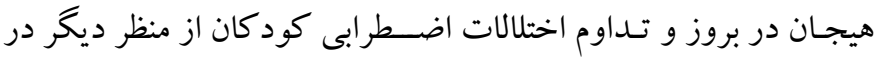
مطالعه حاضـر تأييد شـــ. به نظر مىرســـ فكرهاى مادر (1))، فكرها و

2. Parental accommodation model
سو گيرى شناختى با كنار آمدن وير انخر، معنادار نيست. به عبارتى به نظر

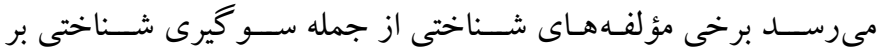

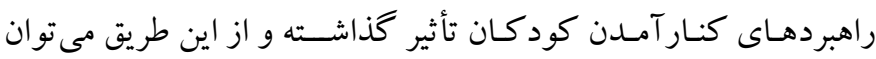
ياسـخ هاى اضطر ابى متفاوتى را شـاهد بود. در تبيين يافته حاضر مى توان

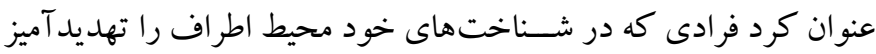

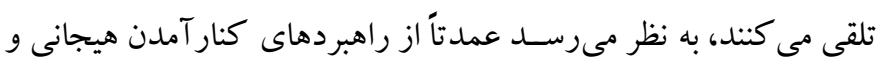
منفى استفاده مى كنند (Yr). از سويى ديخر افر اد با علائم اضطر ابى، وقتى سلى

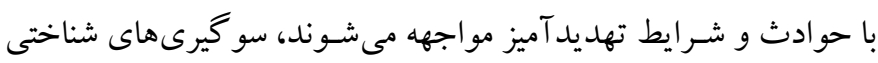

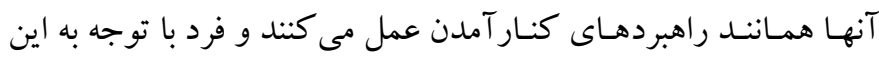

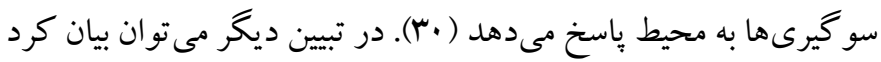

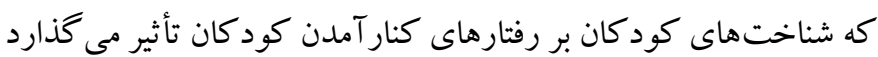

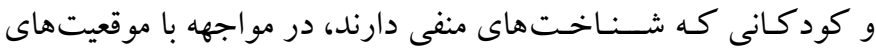

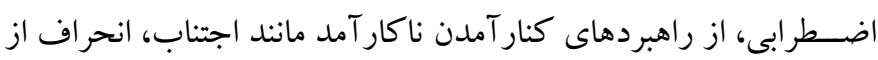

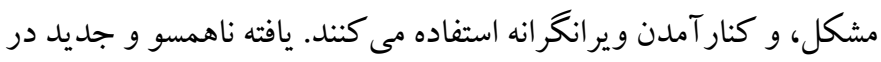
مطالعه حاضر، عدم تأثير مستقيم سو گيرى شناختى كودكك بر اضطراب

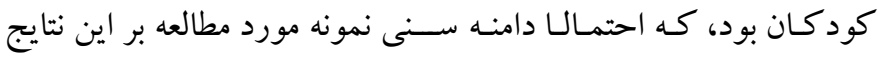
تأثير گذار بوده است، زيرا با افزايش سن، بر مهارتهاى شناختى كود كان لهان افزوده مىشود. همســو با مطالعات بيشــين، نتايج مطالعه حاضـر همجنين نشــان داد

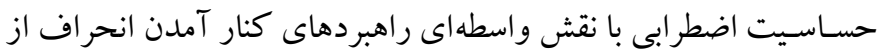

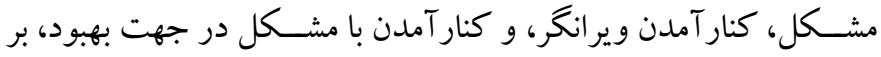
اضـطراب كود كان تأثير دارد (YV و و (YN). وران و كاكس (YV) معتقدند افرادى كه حسـاسيت اضطر ابى بالايى دارند، در مو اجهه با موقعيت هاى اضطر ابى از راهبردهاى كنار آمدن نامناسب استفاده مى كنند. به عبارتى به به به نظر مىرسد كود كانى كه حساسيت اضطر ابى باليى دارند و موقعيتهاى

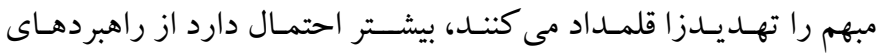
كنار آمدن منفى از جمله انحر اف از مشكل و كنار آمدن ويرانخر استفاده

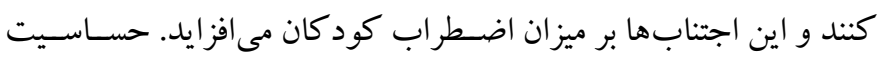

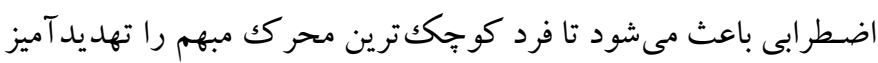

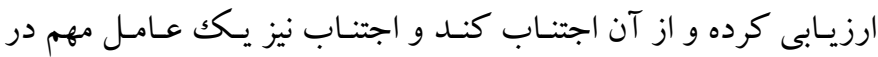
افز ايش اضطراب قلمداد مىشود. 
همجنين امكان حضور اوليا در مدرسه و ياسخ گويى در حضور آزمونگر

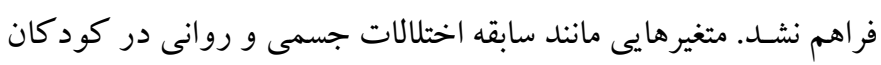

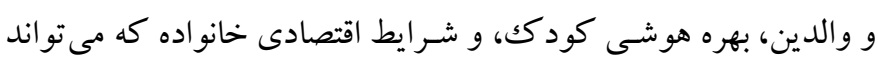

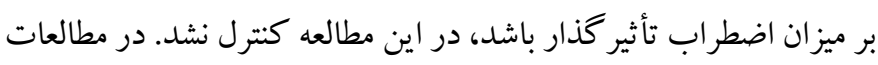

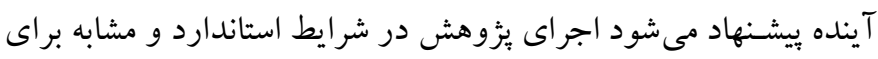

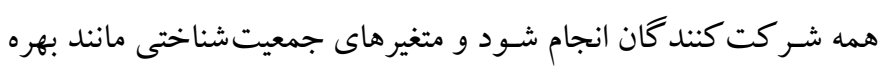

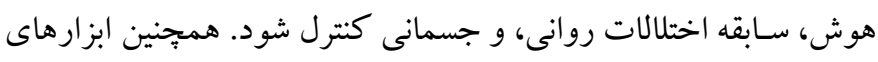

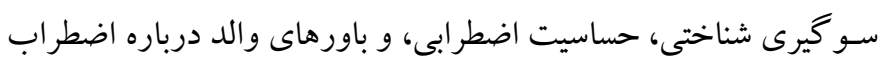

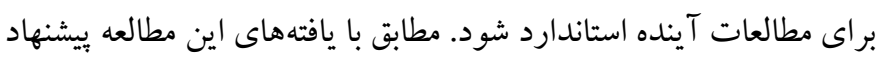

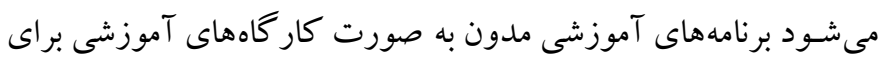
مديريت اضطر اب كود كان و والدين طراحى شـود و با اسـتفاده از نتايج

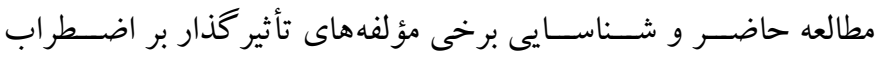

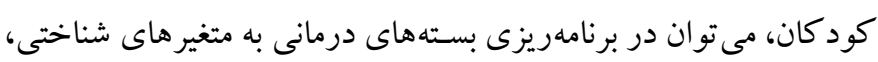

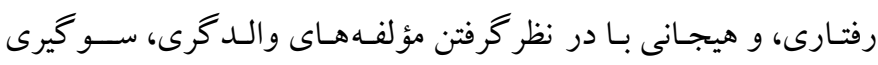

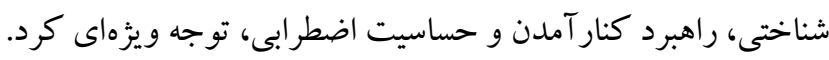

ملاحظات اخلاقى هييروى از اصول اخلاق ثئوهش: اين مطالعه با اخذ مجوزهاى لازم علمى و اجرايى

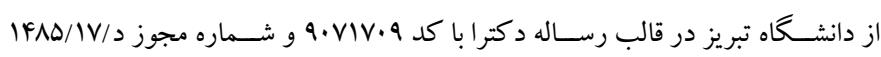

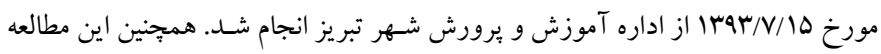
با رضايت كامل افراد نمونه انجام شد.

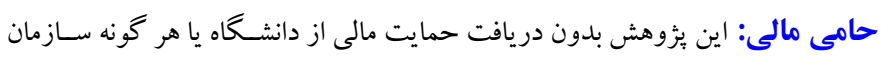

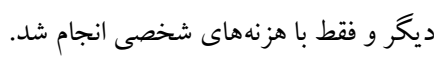

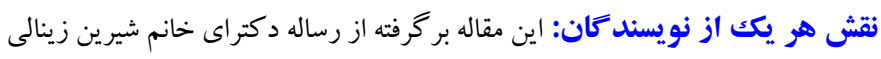

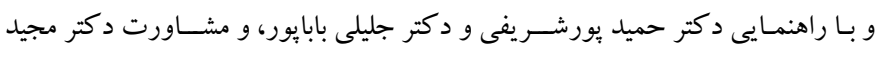

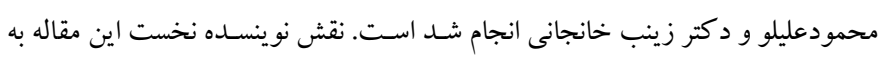

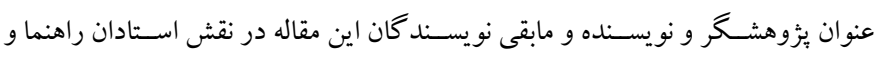
شماور، نقش داشتند.

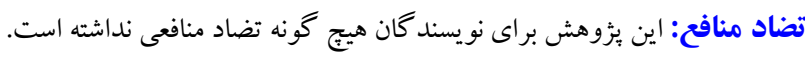

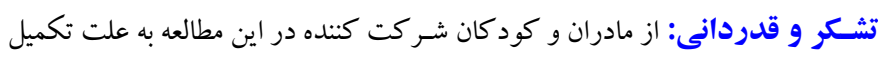

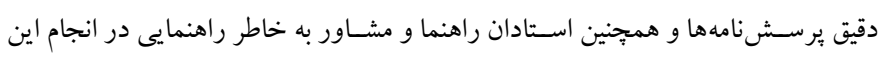

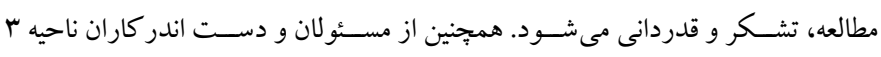

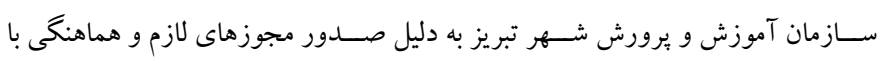

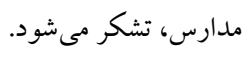

خطاهاى شـناختى كود كك (F)، حساسيت كودك به مؤ لفه هاى اضطر ابى

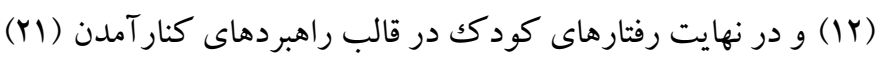

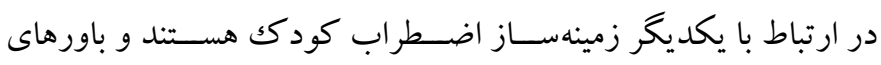

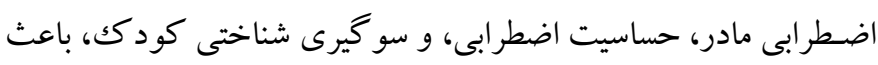

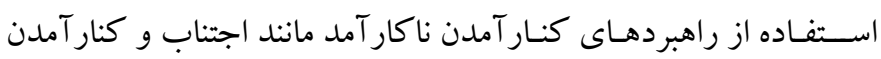
ويرانخر انه شــهـ و در نهايت باعث تشـديد اضـطر اب كود كك مى شــود...

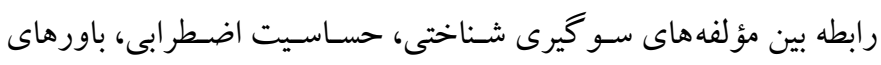

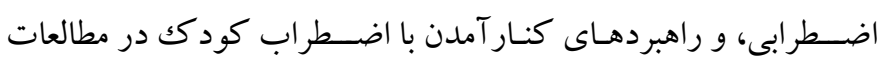

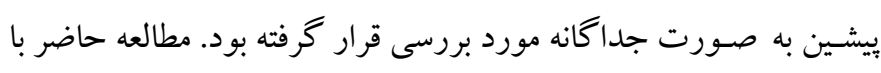

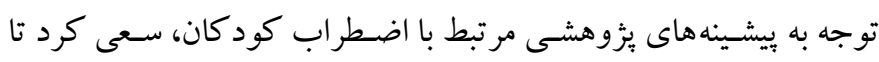

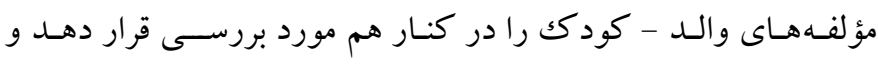

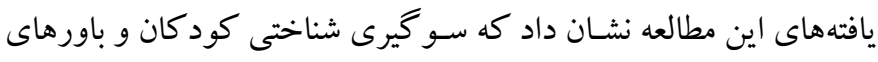

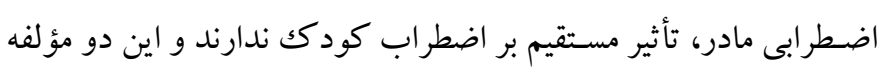

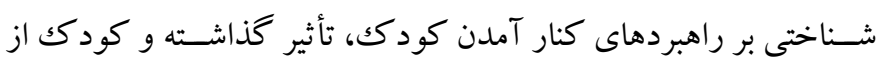

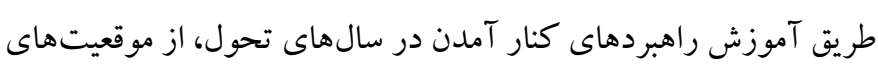

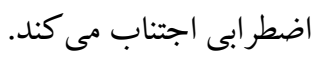
برخى از مطالعـات بيشــــن رابطهه بين اين متغيرهـا را بـا هم مطـالعه

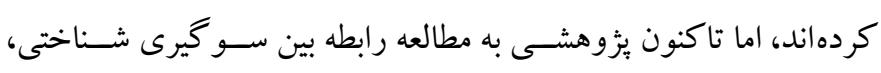

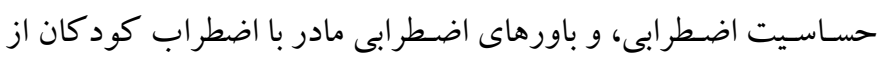

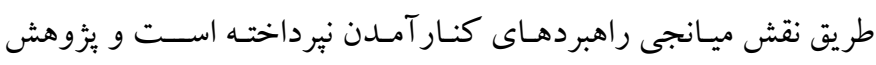

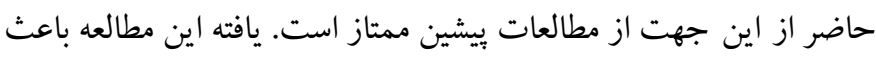

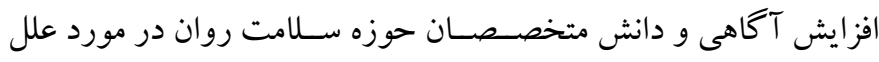

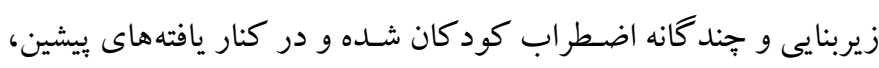

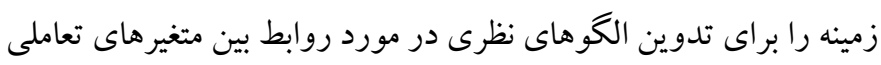
والد - كود كك در شكل گيرى اضطراب فر اهم مى كند. يثزوهش حـاضـــر بـا برخى از محدوديت ها روبرو بود. برخى مفاهيم

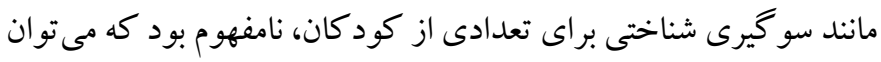

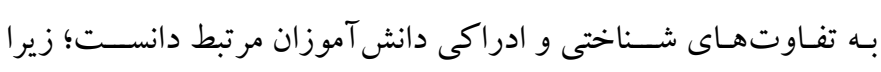
تفاوتهاى مربوط به تحول شـناختى، باعث ادراكك متفاوت مى شـود. بنا به شرايط و قوانين برخى مدارس، امكان حضور آزمونگر در حين تكميل

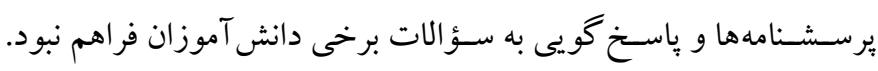




\section{References}

1. Warren SL, Huston L, Egeland B, Sroufe LA. Child and adolescent anxiety disorders and early attachment. Journal of the American Academy of Child \& Adolescent Psychiatry. 1997;36(5):637-44. [Link]

2. Bhatia M, Goyal A. Anxiety disorders in children and adolescents: Need for early detection. J postgraduate medicine. 2018;64(2):75. [Link]

3. Polanczyk GV, Salum GA, Sugaya LS, Caye A, Rohde LA. Annual research review: A meta-analysis of the worldwide prevalence of mental disorders in children and adolescents. J Child Psychol Psychiatry. 2015;56(3):345-65. [Link]

4. Viana AG, Gratz KL. The role of anxiety sensitivity, behavioral inhibition, and cognitive biases in anxiety symptoms: Structural equation modeling of direct and indirect pathways. J Clin Psychol. 2012;68(10):112241. [Link]

5. Viana AG, Kiel EJ, Alfano CA, Dixon LJ, Palmer CA. The contribution of temperamental and cognitive factors to childhood anxiety disorder symptoms: A closer look at negative affect, behavioral inhibition, and anxiety sensitivity. J Child Fam Stud. 2017;26(1):194-204. [Link]

6. Raines EM, Viana AG, Trent ES, Woodward EC, Candelari AE, Zvolensky MJ, et al. Effortful control, interpretation biases, and child anxiety symptom severity in a sample of children with anxiety disorders. Journal of anxiety disord. 2019;67:1102136. [Link]

7. Viana AG, Dixon LJ, Stevens EN, Ebesutani C. Parental emotion socialization strategies and their interaction with child interpretation biases among children with anxiety disorders.J Cognitive Therapy and Research. 2016;40(5):717-31. [Link]

8. Zvolensky MJ, Garey L, Fergus TA, Gallagher MW, Viana AG, Shepherd JM, et al. Refinement of anxiety sensitivity measurement: The Short Scale Anxiety Sensitivity Index (SSASI). J Psychiatry res.2018; 57: 549-569. [Link]

9. aragon-Gainey K. Meta-analysis of the relations of anxiety sensitivity to the depressive and anxiety disorders. J Psychological bulletin. 2010;136 (1):128. [Link]

10.Stassart C, Dardenne B, Etienne AM. The role of parental anxiety sensitivity and learning experiences in children's anxiety sensitivity. Br J Dev Psychol. 2017;35(3):359-75. [Link]

11. Anderson ER, Hope DA. The relationship among social phobia, objective and perceived physiological reactivity, and anxiety sensitivity in an adolescent population. J anxiety disord. 2009;23(1):18-26. [Link]

12. Wauthia E, Lefebvre L, Huet K, Blekic W, El Bouragui K, Rossignol M. Examining the hierarchical influences of the Big-Five dimensions and Anxiety Sensitivity on anxiety symptoms in children. Frontiers in psychology. 2019;10:1185. [Link]

13.Affrunti NW, Woodruff-Borden J. The effect of maternal psychopathology on parent-child agreement of child anxiety symptoms: A hierarchical linear modeling approach. J Anxiety Disord. 2015;32:56-65. [Link]

14.Kerns CE, Pincus DB, McLaughlin KA, Comer JS. Maternal emotion regulation during child distress, child anxiety accommodation, and links between maternal and child anxiety. J Anxiety Disord. 2017;50: 52-59. [Link]

15.Francis SE, Chorpita BF. Development and evaluation of the parental beliefs about anxiety questionnaire. $\mathrm{J}$ Psychopathol Behav Assess. 2010;32(1):138-49. [Link]

16. Krohne HW. Developmental conditions of anxiety and coping: A two-process model of child-rearing effects: Psycholog. Inst., Abt. Persönlichkeitspsychologie; 1990. [Link]

17.O'Connor EE, Langer DA, Comer JS, Tompson MC. A randomized-controlled examination of the effect of cognitive reappraisal instruction on maternal accommodation of child anxiety symptoms. Journal of Anxiety Disorders. 2020;74:102260. [Link]

18. Moghaddam PN, Sepahvand T. The explanation of social anxiety in primary school children based on difficulties in emotional regulation and cognitive flexibility of mothers. Quarterly Journal of Child Mental Health. 2018; 5(2): 14-24. [Link]

19.Salamat MK, Hejazi M, Morovati Z, Isadpanah S. Predicting children's behavioral problems based on maternal parenting styles: The mediating role of child adjustment. Quarterly Journal of Child Mental Health. 2019;6(3):269-80. [Link]

20. Micco JA, Ehrenreich JT. Children's interpretation and avoidant response biases in response to nonsalient and salient situations: Relationships with mothers' threat perception and coping expectations. J Anxiety Disord. 2008;22(3):371-85. [Link]

21.Xiong W, Liu H, Gong P, Wang Q, Ren Z, He M, et al. Relationships of coping styles and sleep quality with anxiety symptoms among Chinese adolescents: A cross-sectional study. J Affect Disord. 2019;257:10815. [Link] 
22.Thomsen AH, Compas BE ,Colletti RB, Stanger C, Boyer MC, Konik BS. Parent reports of coping and stress responses in children with recurrent abdominal pain. J Pediatric Psychology. 2002;27(3):215-26. [Link]

23.Compas BE, Orosan PG, Grant KE. Adolescent stress and coping: Implications for psychopathology during adolescence. J adolesc. 1992;16(3):331. [Link]

24. Holen S, Lervåg $\mathrm{A}$, Waaktaar $\mathrm{T}$, Ystgaard $\mathrm{M}$. Exploring the associations between coping patterns for everyday stressors and mental health in young schoolchildren .J Sch Psychol. 2012;50(2):167-93. [Link]

25.Gerber M, Lindwall M, Brand S, Lang C, Elliot C, Pühse U. Longitudinal relationships between perceived stress, exercise self-regulation and exercise involvement among physically active adolescents. Journal of sports sci.2015;33(4):369-80. [Link]

26. Abdi R, Kaboodi N. Moderating role of experiential avoidance in the relationship between anxiety sensitivity and perceived stress. J Andisheh va Raftar. 2016; 10(40):10-66. [Link]

27. Werhun CD, Cox BJ. Levels of anxiety sensitivity in relation to repressive and self-deceptive coping styles. Journal of anxiety disord. 1999;13(6):601-9. [Link]

28.Keogh E, Mansoor L. Investigating the effects of anxiety sensitivity and coping on the perception of cold pressor pain in healthy women. Eur J Pain. 2001; 5(1):11-22. [Link]

29.Compas BE, Connor-Smith JK, Saltzman H, Thomsen $\mathrm{AH}$, Wadsworth ME. Coping with stress during childhood and adolescence: problems, progress, and potential in theory and research. J Psychological bulletin. 2001;127(1):87. [Link]

30.Legerstee JS, Garnefski N, Verhulst FC, Utens EM. Cognitive coping in anxiety-disordered adolescents. J adolesc. 2011;34(2):319-26. [Link]

31.Garnefski N, Kraaij V, Spinhoven P. Negative life events, cognitive emotion regulation and emotional problems. Pe J Pers Individ Dif. 2001;30(8):1311-27. [Link]

32.Dias C, Cruz JF, Fonseca AM. The relationship between multidimensional competitive anxiety, cognitive threat appraisal, and coping strategies: A multi-sport study. Int $\mathbf{J}$ Sport Exerc Psychol. 2010;10(1):52-65. [Link]
33.Kashdan TB, Zvolensky MJ, McLeish AC. Anxiety sensitivity and affect regulatory strategies: Individual and interactive risk factors for anxiety-related symptoms. J anxiety disord. 2008;22(3):429-40. [Link]

34.Hooman HA. Structural equation modeling with LISREL software application. Tehran: SAMT. 2009.

35.Kingery JN, Ginsburg GS, Burstein M. Factor structure and psychometric properties of the Multidimensional Anxiety Scale for Children in an African American adolescent sample. J Child Psychiatry Hum Dev t. 2009;40(2):287-300. [Link]

36. Mashhadi A, Soltani SR, Mirdoraghi F, Bahrami B. Psychometric properties of the multidimensional anxiety scale for Iranian children. JNKUMS. 2015, 4(4): 885-849. [Link]

37.Hernandez B. The children's coping behavior questionnaire: Development and validation [MA thesis]. Chicago: Loyola University Chicago. 2008. [Link]

38. Fallahi M, Kafie Masuleh M, Khousro Javid M, Karimi Lie Chahei R, Eskandari B. A Preliminary Evaluation of the Psychometric Properties of the Children's Coping Behavior Questionnaire (CCBQ). Iranian Journal of Psychiatry and Clinical Psychology. 2018;23(4):494-509. [Link]

39. Covin R, Dozois DJ, Ogniewicz A, Seeds PM. Measuring cognitive errors: Initial development of the Cognitive Distortions Scale (CDS). Int J Cogn Ther. 2011;4(3):297-322. [Link]

40.Tsao JC, Lu Q, Myers CD, Kim SC, Turk N, Zeltzer LK. Parent and child anxiety sensitivity: relationship to children's experimental pain responsivity. J Pain. 2006;7(5):319-26. [Link]

41.Kline RB. Principles and practice of structural equation modeling: Guilford publications; 2015.

42.Gefen D, Straub D, Boudreau M-C. Structural equation modeling and regression: Guidelines for research practice. Communications of the association for information systems. 2000; 3(1). [Link] 